\title{
Fatty acids and lymphocyte functions
}

\author{
P. C. Calder*, P. Yaqoob†, F. Thies, F. A. Wallace and E. A. Miles \\ Institute of Human Nutrition, University of Southampton, Bassett Crescent East, Southampton, SO16 7PX, UK
}

\begin{abstract}
The immune system acts to protect the host against pathogenic invaders. However, components of the immune system can become dysregulated such that their activities are directed against host tissues, so causing damage. Lymphocytes are involved in both the beneficial and detrimental effects of the immune system. Both the level of fat and the types of fatty acid present in the diet can affect lymphocyte functions. The fatty acid composition of lymphocytes, and other immune cells, is altered according to the fatty acid composition of the diet and this alters the capacity of those cells to produce eicosanoids, such as prostaglandin $E_{2}$, which are involved in immunoregulation. A high fat diet can impair lymphocyte function. Cell culture and animal feeding studies indicate that oleic, linoleic, conjugated linoleic, $\gamma$-linolenic, dihomo- $\gamma$-linolenic, arachidonic, $\alpha$-linolenic, eicosapentaenoic and docosahexaenoic acids can all influence lymphocyte proliferation, the production of cytokines by lymphocytes, and natural killer cell activity. High intakes of some of these fatty acids are necessary to induce these effects. Among these fatty acids the long chain $n$ - 3 fatty acids, especially eicosapentaenoic acid, appear to be the most potent when included in the human diet. Although not all studies agree, it appears that fish oil, which contains eicosapentaenoic acid, down regulates the T-helper 1-type response which is associated with chronic inflammatory disease. There is evidence for beneficial effects of fish oil in such diseases; this evidence is strongest for rheumatoid arthritis. Since $n$-3 fatty acids also antagonise the production of inflammatory eicosanoid mediators from arachidonic acid, there is potential for benefit in asthma and related diseases. Recent evidence indicates that fish oil may be of benefit in some asthmatics but not others.
\end{abstract}

Fatty acid: Fish oil: Lymphocyte: Monocyte: Cytokine: Eicosanoid: Inflammation: Immunity

\section{Introduction}

Interest in the effects of fatty acids upon the immune system dates back many years, but this interest intensified with the elucidation of the roles of eicosanoids derived from arachidonic acid (ARA; 20:4n-6) in modulating inflammation and immunity and with the knowledge that the metabolism of ARA to yield these mediators can be inhibited by the long chain $n-3$ polyunsaturated fatty acids (PUFA) found in fish oils. This article will review the effects of fatty acids upon lymphocyte proliferation, lymphocyte-mediated cytotoxicity, lymphocyte-derived cytokine production, antibody production, and cellmediated immunity. Since lymphocytes are activated in vivo by presentation of antigen by antigen-presenting cells and by cytokines derived from them, this review will also describe the effects of fatty acids on these processes. These, and other, aspects of fatty acids and immunity have been reviewed a number of times (Calder, 1995, 1996a,b, 1997, 1998a,b,c, 1999; Blok et al. 1996; Alexander, 1998; Grimble, 1998; Harbige, 1998; Hughes, 1998; Miles \& Calder, 1998; Sperling, 1998; Wu \& Meydani, 1998; Yaqoob, 1998 $a, b)$ and the reader is referred to these articles for a more complete overview of the field. Mechanisms by which fatty acids might influence the functions of lymphocytes, apart from effects upon eicosanoid production, will not be reviewed here; these have been discussed elsewhere (Calder 1996b; Miles \& Calder 1998; Yaqoob, 1998b).

\section{Lymphocytes}

Lymphocytes are the cells that specifically recognise and respond to foreign antigens and, as such, they form the core of the acquired (or specific) immune system. They are

\footnotetext{
Abbreviations: EPA, eicosapentaenoic acid; ARA, arachidonic acid; PUFA, polyunsaturated fatty acid; GLA, $\gamma$-linolenic acid; DGLA, di-homo- $\gamma$-linolenic acid; ALNA, $\alpha$-linolenic acid; DHA, docosahexaenoic acid; NK, natural killer; Th-lymphocyte, helper T-lymphocyte; CTL, cytotoxic T-lymphocyte; MHC, major histocompatibility complex; DTH, delayed type hypersensitivity; MNC, mononuclear cell.

* Corresponding author: Dr P. C. Calder, fax 44 (0) 238059 4383, email pcc@ soton.ac.uk

$\dagger$ Present address: Hugh Sinclair Unit of Human Nutrition, School of Food Biosciences, University of Reading, Whiteknights, Reading RG6 6AP, UK
} 
present as circulating cells in blood and lymph, as anatomically defined collections of cells in lymphoid organs (thymus, spleen, lymph nodes, gut-associated lymphoid tissue) or as scattered cells in other tissues. Lymphocytes exist as distinct subsets that are quite different in their functions and protein products, although they are morphologically fairly similar. The principal types of lymphocytes are T- and B-lymphocytes and natural killer (NK) cells.

\section{T-lymphocytes}

The precursors of T-lymphocytes arise in the bone marrow and mature in the thymus. T-lymphocytes are further subdivided into functionally distinct populations, the best defined of which are helper T-lymphocytes (Th-lymphocytes) and cytotoxic T-lymphocytes (CTL); these classes of $\mathrm{T}$-lymphocyte are characterised by the presence of CD4 or
CD8 molecules, respectively, on their surface. T-lymphocytes recognise peptide antigens attached to major histocompatibility complex (MHC) proteins on the surface of so-called antigen presenting cells. MHC II is expressed on dendritic cells, monocytes and macrophages, and B-lymphocytes. The role of MHC II is the presentation of antigenic peptides derived from intracellular proteins of exogenous origin to the T-cell receptor-CD3 complex on $\mathrm{CD}^{+}$(Th) lymphocytes (Fig. 1). MHC I is expressed on most cells, but the level of expression varies among different cell types. The role of MHC I is the presentation of antigenic peptides derived from intracellular proteins of endogenous origin to the $\mathrm{T}$-cell receptor-CD3 complex on $\mathrm{CD}^{+}$lymphocytes (CTL). Thus, the MHC I-CTL interaction is involved in the destruction of cells infected with viruses. The MHC-T-cell receptor interaction on its own is insufficient to promote T-lymphocyte activation even in the presence of CD4 or CD8; other interactions

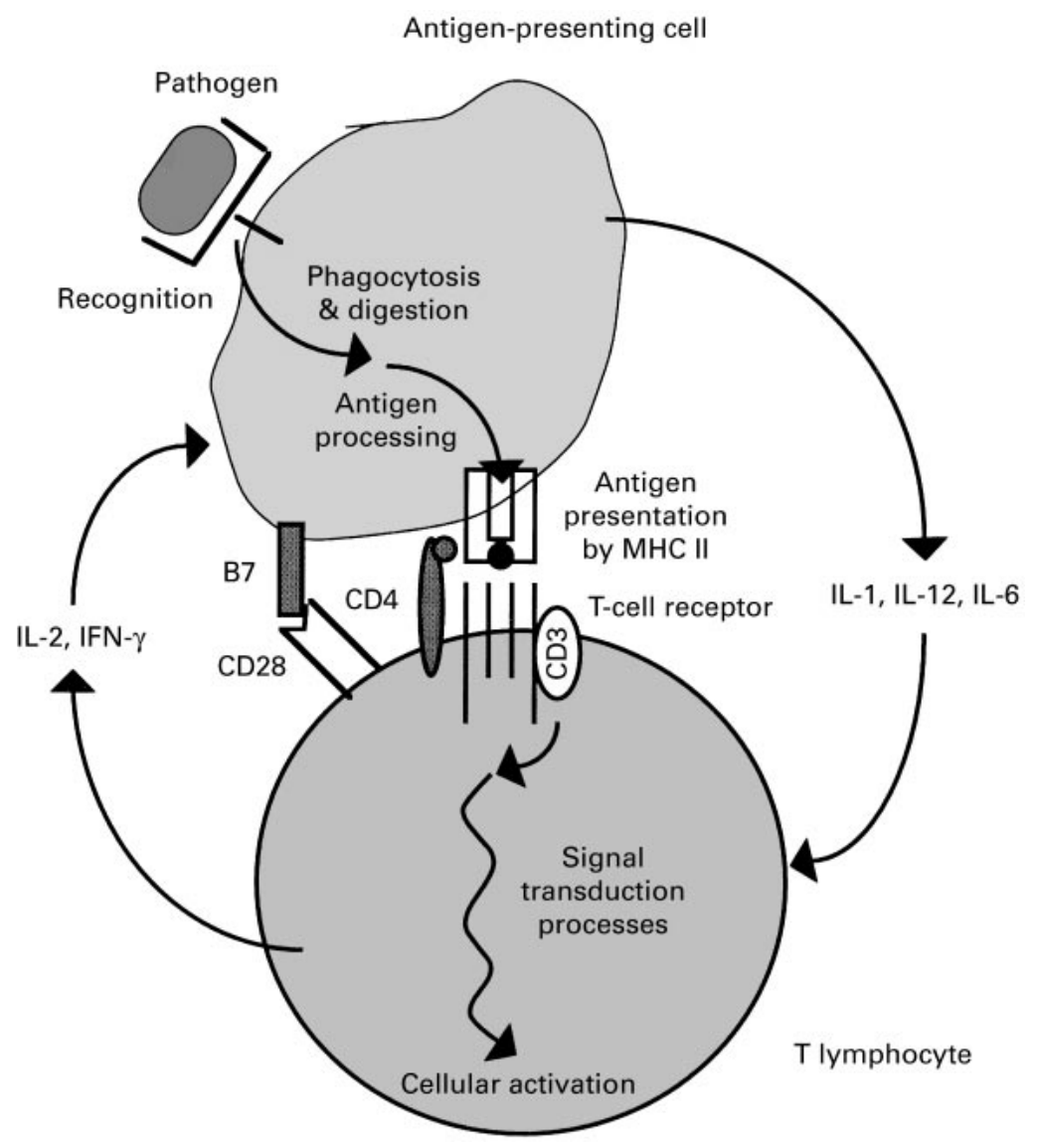

Fig. 1. The interaction between antigen presenting cells and T-lymphocytes. In the example shown, an extracellular pathogen is recognised and phagocytosed by an antigen presenting cell; this process is enhanced by coating of the pathogen with complement or antibodies (not shown). The phagocytic vesicle containing the pathogen fuses with a lysosome and the pathogen is subsequently digested. Peptides from the pathogen associate with MHC II and are translocated to the cell surface. The peptide is presented to the T-cell receptor on the T-lymphocyte surface. The interaction between MHC II and the T-cell receptor is stabilised by CD4 (CD8 stabilises the interaction between MHC I and the T-cell receptor), while accessory molecules on the surface of each cell (e.g. B7 and CD28) interact to provide further stability. CD3 tranduces signals from the T-cell receptor into the T-lymphocyte. Both the antigen presenting cell and the T-lymphocyte secrete cytokines to influence the activities of one another. 
between molecules on the surface of the antigen presenting cell and the T-cell are required (e.g. B7 and CD28). These molecules are termed accessory molecules.

In response to stimulation T-lymphocytes secrete cytokines whose function is to promote an increase in T-lymphocyte number (termed lymphocyte proliferation), the differentiation of T-lymphocytes and the activation of other cell types including B-lymphocytes, NK cells and macrophages.

The Th-lymphocytes are further sub-divided according to the pattern of cytokines they produce (Fig. 2). Upon initial encounter with antigen naive Th-cells produce mainly interleukin-2 (IL-2). These cells may differentiate into a population sometimes referred to as Th0 cells which differentiate further into either Th1 or Th2 cells (Fig. 2); this is a simplistic view and it is now recognised that there are most likely other classes of Th cell (e.g. Th3) (Mossmann \& Sad, 1996). The differentiation into Th1 or Th2 is regulated by cytokines: IL-12 and IFN- $\gamma$ promote the development of Th1 cells, while IL-4 promotes the development of Th2 cells (Fig. 2). Th1 and Th2 themselves have relatively restricted profiles of cytokine production: Th1 cells produce IL-2 and IFN- $\gamma$ which activate macrophages, NK cells and CTL and are the principal effectors of cell-mediated immunity and delayed type hypersensitivity (DTH). Intracellular pathogens tend to induce Th1 activity. This is because antigen presenting cells are a major source of IL-12. Thus, infection with intracellular pathogens will promote differentiation along the Th1 pathway, and this will in turn produce cytokines which promote the activity of cells able to destroy such pathogens (e.g. macrophages, CTL, NK cells) and the immunoglobulin (Ig) G-type of antibody response (Fig. 2). Th2 cells produce IL-4, which stimulates IgE production, IL-5, an eosinophil activating factor, and IL-10, which together with IL-4 suppresses cell-mediated immunity and inflammation (Fig. 2). Infection with extracellular pathogens, such as helminthic worms, tends to induce differentiation along the Th2 pathway, and this will in turn induce responses which are able to destroy such pathogens, e.g. IgE production (Fig. 2). One important aspect of the Th1-Th2 paradigm is that Th1-type cytokines, especially IFN- $\gamma$, inhibit the differentiation of Th2 cells, while Th2-type cytokines, especially IL-4, inhibit the differentiation of Th1 cells, Fig. 2 (Mossmann \& Sad, 1996).

\section{B-lymphocytes}

B-lymphocytes mature in the bone marrow. They are the cells responsible for producing antibodies. The role of these antibodies is to neutralise and promote elimination of the antigen that induced their formation (Fig. 2). The antibodies produced belong to different Ig classes depending upon the type of stimulus and the anatomical site of the lymphocytes involved. Cytokines determine the types of antibodies produced by selectively promoting Ig heavy chain class switching and by stimulating B-lymphocyte proliferation. The most potent cytokines involved in B-lymphocyte activation are those produced by Th cells (Fig. 2).

\section{NK cells}

These are a class of lymphocyte which do not express surface markers identifying them as either T- or B-lymphocytes. They are capable of lysing tumour or virus-infected cells and have a role in graft rejection. NK cells are activated by IL-2, IL-12, IFN- $\gamma$ and tumour necrosis factor (TNF)- $\alpha$.

\section{Lymphocytes in health and disease}

Clearly a well functioning immune system is essential to health. It serves to protect the host from the effects of ever present pathogenic organisms. Cells of the immune system also have a role in identifying and eliminating cancer cells. There are however some detrimental effects of the immune system and lymphocytes are central to these effects. First, in the course of its activity to recognise and eliminate foreign antigens, the immune system is responsible for the rejection of transplanted tissues. Second, in some individuals the immune system appears to recognise host antigens as "nonself' rather than as 'self'. As a result, an immune response to host tissues is generated and this leads to tissue damage. This is the characteristic of so-called chronic inflammatory or autoimmune diseases. Such diseases are linked to genes coding for proteins involved in antigen presentation or recognition such as the MHC II proteins and the T-cell receptor; thus there is a genetic predisposition to these diseases. These diseases are typified by an ongoing chronic inflammation involving the pro-inflammatory cytokines produced by monocytes and macrophages and by a dysregulated Th1 lymphocyte response. Examples of this type of disease include rheumatoid arthritis, type-1 diabetes, Crohn's disease, psoriasis, and multiple sclerosis. Third, the immune system of some individuals can become sensitised to usually benign antigens from the environment and can respond inappropriately to them by the release of IgE. Such antigens can include components of foods or of so-called allergens (e.g. cat or dog fur, house dust mite, some pollens), such that this response can lead to allergies, asthma and related atopic diseases. Although these diseases are also termed chronic inflammatory diseases they have a different immune basis from the diseases described above, although again they are typified by inappropriate recognition of and/ or responses to antigens. However, atopic diseases are characterised by a dysregulated Th2 lymphocyte response such that excessive amounts of IL-4, IL-5 and IL-10 are found. IL-10 suppresses the Th1 response, IL-4 stimulates $\mathrm{IgE}$ production by B-lymphocytes (IgE promotes histamine release from mast cells), and IL-4 and IL-5 activate eosinophils which are involved in the persistent inflammation which is a characteristic of these diseases.

\section{Assessment of the effect of fatty acids on lymphocyte function}

\section{General considerations}

There is a wide range of methodologies available by which to assess the impact of fatty acids on specific lymphocyte functions. In vitro studies adding pure fatty acids, fatty acid mixtures or other lipids (e.g. triacylglycerols, phospholipids, 


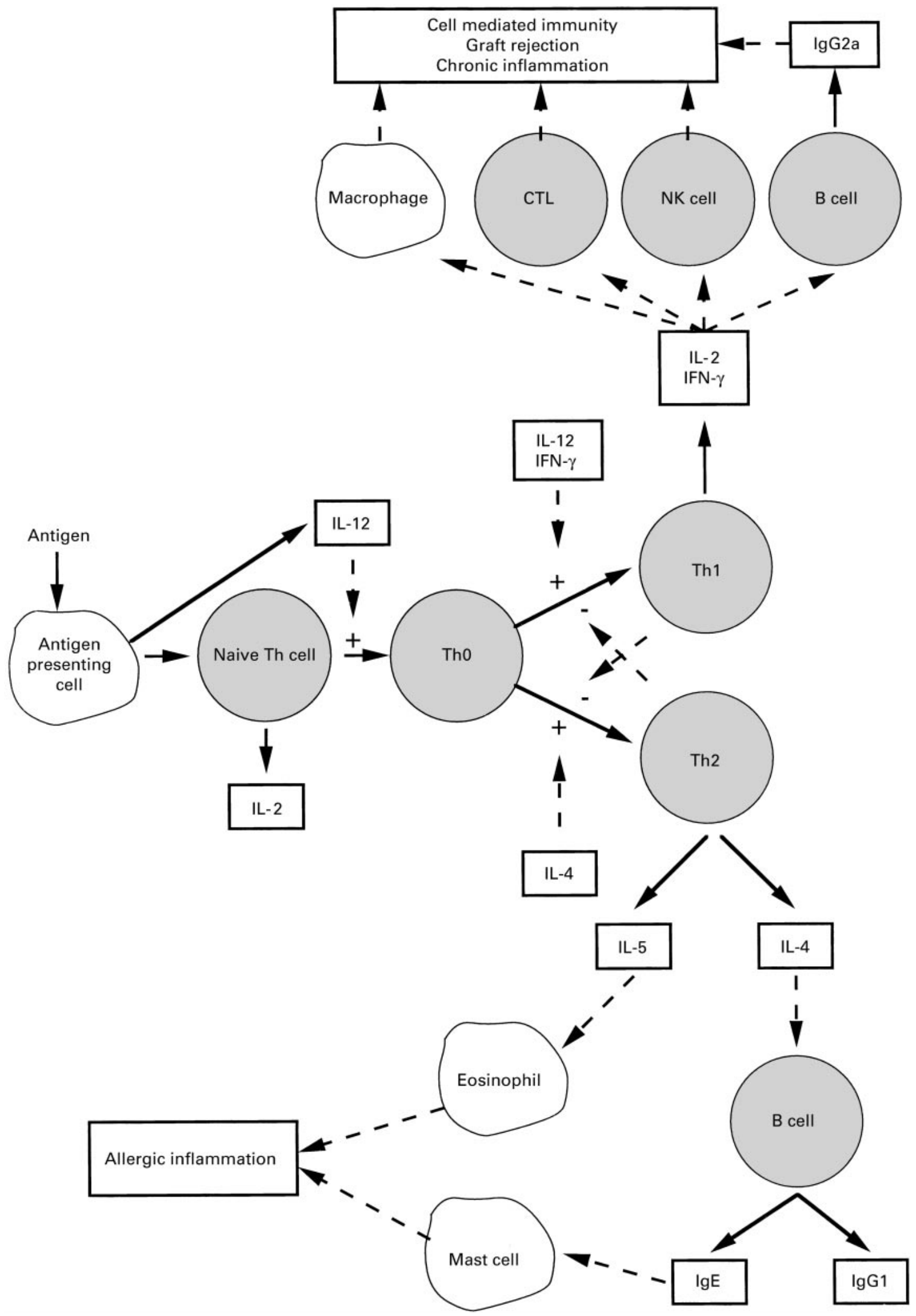

Fig. 2. The differentiation and roles of Th1 and Th2 lymphocytes. $\rightarrow$ indicates produces; --- indicates regulates. 
lipoproteins) to lymphocytes in culture can be used; these studies use conditions which are highly controlled, although they are often rather unphysiological in nature. For example, the cells are cultured in isolation from the other types of cells with which they would come into contact in the body and the concentrations of fatty acids added to the cultures are often greatly in excess of those which can be attained in vivo. The effects of changing the amounts or types of fat in the diet on lymphocyte functions can be studied by isolating lymphocytes from animals or humans which have undergone dietary changes and culturing them ex vivo. While this has some of the disadvantages of the pure in vitro approach, its controlled nature allows effects on specific cell types and functions to be assessed and allows the exploration of the mechanisms underlying functional changes. One solution to the problem of using isolated lymphocytes in culture has been the development of whole blood culture systems (e.g. Yaqoob et al. 1999), which have been used in some studies investigating the influence of dietary fatty acids in animals (Yaqoob et al. 1995) and humans (Yaqoob et al. 2000). Clearly one limitation to the isolation and subsequent culture of lymphocytes is having a suitable source. For animal studies this does not represent a problem and lymphocytes from the bloodstream, spleen, thymus, lymph nodes, lungs and gut-associated lymphoid tissue are accessible and have been studied. However, most human studies have been restricted to using blood lymphocytes, often as a mixture with monocytes. Preparations containing such mixtures of lymphocytes and monocytes are often described as mononuclear cell (MNC) preparations; typically a MNC preparation from human peripheral blood would comprise 85-90\% lymphocytes and 10-15\% monocytes. One other important difference between dietary experiments in animals and humans is that animal experiments have often used very high amounts of the fatty acids under investigation and these represent intakes that could never be achieved in humans. While the use of such dietary regimens means that effects can be established and mechanisms studied, it is important that the effects of fatty acids at levels in the animal diet relevant to human consumption be demonstrated and that effects be determined in humans under appropriate conditions.

\section{Measures using isolated cells}

Probably the most widely used indicator of lymphocyte function is proliferation, i.e. the ability of the cells to divide when stimulated. Most often this is measured as the incorporation of radioactively-labelled thymidine into the DNA of the dividing lymphocytes, although a number of other measures are available. Agents used to stimulate lymphocyte proliferation include mitogens like concanavalin A (Con A) and phytohaemagglutinin (PHA), which stimulate T-lymphocytes, pokeweed mitogen, which stimulates a mixture of $\mathrm{T}$ - and B-lymphocytes, and bacterial lipopolysaccharide (LPS), which stimulates B-lymphocytes (and also monocytes). T-lymphocyte proliferation can also be triggered by using antibodies to CD3 or to CD3 in combination with antibodies to other surface proteins (e.g. CD4) or by a combination of agents which stimulate protein kinase $\mathrm{C}$ and a rise in the intracellular free calcium concentration. If the animal or individual has been sensitised to an antigen (or allergen) then the antigen (or allergen) can be used to stimulate lymphocyte proliferation. The proliferative response to the antigen or allergen will be much smaller than the response to mitogens or antibodies, since the antigenic response is specific, targeting only those T-lymphocytes which recognise the antigen; in contrast mitogenic stimulation is non-specific and will target a large proportion, perhaps all, of T- or B-lymphocytes in the cell preparation. In response to stimulation with mitogen, antibodies, antigen or allergen, lymphocytes will produce cytokines (e.g. IL-2, IFN- $\gamma$, IL-4, IL-10, IL-6) and the concentrations of these can be measured. LPS stimulation of monocytes, macrophages or MNC leads to production of TNF- $\alpha$, IL- 1 and IL-6. B-lymphocytes produce Ig in culture and the total concentration of particular Ig classes (e.g. IgG) can be measured, as can the concentration of Ig for a specific antigenic (or allergenic) stimulus. The cell surface expression of molecules involved in cell-cell interaction (e.g. adhesion molecules), in antigen presentation (e.g. MHC II) and in cellular activation (e.g. cytokine receptors) can be measured, as can the ability of antigen presenting cells to present antigen to sensitised T-lymphocytes. NK cell and CTL activity can be measured as the killing of tumour cells or virally-infected cells known to be specific targets for these cells.

\section{In vivo measures}

The effects of changing the amounts or types of fat in the diet can also be studied by assessing certain indicators of lymphocyte function in vivo, particularly in response to an immunological challenge. Clearly, animals offer greater access to the immune system, but it is important that observations made in animal studies be confirmed in humans. The number, types and percentages of lymphocytes circulating in the bloodstream and the cell surface expression of molecules involved in cell-cell interaction, antigen presentation, and cellular activation can be measured using staining procedures. The size and cellularity (the numbers and types of cells present) of lymphoid organs can be determined. In animal studies the thymus, spleen, lymph nodes and some components of the gut-associated lymphoid tissue can be removed and weighed. In human studies thymus size can be estimated by imaging techniques. The concentrations of total Ig and of the Ig subclasses in the bloodstream can be measured, as can the circulating concentrations of Ig specific for antigens after an antigen challenge or vaccination. Secretory $\operatorname{IgA}(\operatorname{sgA})$ is found in extracellular fluids and its concentration in saliva, tears and intestinal washings can be measured. Circulating concentrations of cytokines and soluble cytokine receptors can be measured. The overall cell-mediated immune response can be determined by assessing responses to challenges known to involve T-lymphocytes. For example, the DTH response to intradermal application of an antigen to which the individual has already been exposed has been used in some human studies; the response is measured as the size of the swelling (termed induration) around the area of application at a period (usually $48 \mathrm{~h}$ ) after the application. In animal studies the ability to reject grafted tissues, especially skin, has been used. 


\section{Variation in lymphocyte responses}

Variation in cellular responses among individuals is not a great problem in animal studies since these most often use inbred strains. However, it is important to note that any particular response will differ among animal species and even among different strains within a species (Table 1). It is highly likely that immune cells from different species and strains will exhibit different sensitivities to the amount of fat in the diet and to different types of dietary fatty acids. Thus, extrapolations from animal studies to humans should be made cautiously.

There is wide variation in lymphocyte responses among healthy human subjects (Table 2). This is in part related to genetic polymorphisms which regulate the expression of cytokines, cytokine receptors, MHC II (in humans this is termed human leucocyte antigen or HLA), adhesion molecules and so on. However, other factors such as age, gender, smoking habits, habitual levels of exercise, alcohol consumption, diet, stage in the female menstrual cycle, and history of infections and vaccinations are likely to be important contributors to the observed variation. Consideration of this variation is important when designing and interpreting human studies. It is not clear whether there is variation in responsiveness of human lymphocytes to the effects of dietary fatty acids, although one study suggests that among women this varies with age (Meydani et al. 1991).

\section{Eicosanoids: a link between fatty acids and lymphocyte functions}

\section{Eicosanoids}

Eicosanoids are a group of chemical messengers synthesised from the 20-carbon PUFA dihomo- $\gamma$-linolenic acid (DGLA; 20:3n-6), ARA and eicosapentaenoic acid (EPA; 20:5n-3). Eicosanoids include prostaglandins (PG), thromboxanes (TX), leukotrienes (LT), lipoxins, hydroperoxy-eicosatetraenoic acids and hydroxyeicosatetraenoic acids (HETE). The fatty acid precursor for eicosanoid synthesis is released from cell membrane phospholipids, usually by the action of phospholipase $\mathrm{A}_{2}$ activated in response to a cellular stimulus. Because the membranes of most cells contain large amounts of ARA, compared with DGLA and EPA, ARA is usually the principal precursor for eicosanoid synthesis and gives rise to the 2-series PG and TX and the

Table 1. Cytokine production by spleen lymphocytes from two different stains of mice

\begin{tabular}{lllll}
\hline \multirow{2}{*}{ Mouse strain } & \multicolumn{4}{c}{ Concentration (pg/ml) } \\
\cline { 2 - 5 } & IL-2 & IFN- $\gamma$ & IL-4 & IL-10 \\
\hline C57BI/6 & $660(60)$ & $510(15)$ & $92(10)$ & $72(10)$ \\
Balb/c & $1100(50)^{\star}$ & $35(5)^{*}$ & $275(25)^{*}$ & $170(15)^{*}$ \\
\hline
\end{tabular}

Spleen lymphocytes from male $\mathrm{C} 57 \mathrm{BI} / 6$ and Balb/c mice (weighing approximately $24 \mathrm{~g}$ ) were prepared by standard techniques and were cultured for $48 \mathrm{~h}$ in the presence of $2.5 \mu \mathrm{g} / \mathrm{ml}$ Con A. Cytokine concentrations in the culture supernatants were measured by specific ELISA. Data are mean (SEM) for four separate cell preparations and are previously unpublished. *Indicates significantly different from C57B1/6. 4-series LT (Fig. 3). PG and TX are produced by the cyclooxygenase enzymes (COX 1 and COX 2), while LT and related compounds are produced by lipoxygenase enzymes (LOX) of which there are three types (5-, 12- and 15-LOX). Lymphocytes are poor sources of eicosanoids (Goldyne, 1988), although they are subject to regulation by them. $\mathrm{PGE}_{2}$ inhibits lymphocyte proliferation, NK cell activity and the production of Th1 cytokines (IL-2, IFN- $\gamma$ ) (see Kinsella et al. 1990; Roper \& Phipps, 1994 for reviews). $\mathrm{PGE}_{2}$ also inhibits MHC II expression and the production of TNF- $\alpha$ and IL- $1 \beta$ by monocytes and macrophages (see Kinsella et al. 1990; Roper \& Phipps, 1994). In contrast, $\mathrm{PGE}_{2}$ does not appear to directly influence the production of the Th2 cytokine IL-4 and promotes IgE production by B-lymphocytes (see Roper \& Phipps, 1994). $\mathrm{LTB}_{4}$ enhances production of TNF- $\alpha$, IL-1 and IL- 6 by monocytes and macrophages, enhances Th1 cytokine production and enhances NK cell activity (see Kinsella et al. 1990; Lewis et al. 1990 for reviews). Thus, ARA gives rise to mediators with opposing actions. Therefore, the overall effect will depend upon the timing of production of the different eicosanoids and upon the sensitivity of target cells to the concentrations of the different eicosanoids produced.

\section{$\gamma$-Linolenic acid and eicosanoids}

$\gamma$-Linolenic acid (GLA; 18:3n-6) is found in borage, blackcurrant seed and evening primrose oils where it contributes about $20-25 \%, 15-20 \%$ and $5-10 \%$ of fatty acids, respectively. Apart from the presence of GLA, these oils tend to resemble typical $n$-6 PUFA-rich vegetable oils with a high content of linoleic acid (18:2n-6), although blackcurrant seed oil also contains $\alpha$-linolenic acid (ALNA; 18:3n-3). GLA does not accumulate in cell membranes, even when it is provided in the diet (Rossetti et al. 1997; Yaqoob et al. 2000). Instead, the content of its derivative, DGLA, is increased (Rossetti et al. 1997; Johnson et al. 1997; Yaqoob et al. 2000) (Table 3). The significance of this is that DGLA is a substrate for COX, giving rise to the 1-series PG (e.g. $\mathrm{PGE}_{1}$ ), for 5-LOX giving rise to 3-series LT and for 15-LOX, giving rise to 15-hydroxy-DGLA (Fig. 3). Like $\mathrm{PGE}_{2}, \mathrm{PGE}_{1}$ inhibits IL-2 and IFN- $\gamma$ production by lymphocytes (Gold et al. 1994), inhibits lymphocyte proliferation (Santoli et al. 1990) and inhibits TNF, IL-1 and IL-6 production by macrophages (Haynes et al. 1992). 15-hydroxy-DGLA is an inhibitor of 5-LOX (Iverson et al. 1991, 1992), and so can decrease the synthesis of some ARA-derived mediators (Iverson et al. 1991, 1992). Supplementing the diet of healthy humans with GLA results in increased $\mathrm{PGE}_{1}$ production and decreased production of $\mathrm{PGE}_{2}, \mathrm{LTB}_{4}$ and $\mathrm{LTC}_{4}$ (Pullman-Moar et al. 1990; Johnson et al. 1997; Wu et al. 1999).

\section{n-3 Polyunsaturated fatty acids and eicosanoids}

Fish oil contains the long chain $n$-3 PUFA EPA, docosapentaenoic acid (22:5n-3) and docosahexaenoic acid (DHA; 22:6n-3). Feeding humans increased amounts of fish oil results in an increase in the amount of EPA and DHA in the membranes of cells involved in inflammation such as 
Table 2. Variation in lymphocyte responses among healthy adult humans

\begin{tabular}{llll}
\hline Subjects & $\begin{array}{c}\text { Thymidine incorporation } \\
(\mathrm{cpm} / \text { well)† }\end{array}$ & $\begin{array}{c}\text { IL-2 production } \\
(\mathrm{pg} / \mathrm{ml}) \boldsymbol{9}\end{array}$ & $\begin{array}{c}\text { NK cell activity } \\
\text { (\% Cytolysis) }\end{array}$ \\
\hline Males aged 18 to 40y; $n=48$ & $48722(38742,57277)$ & $453 \cdot 6(344 \cdot 4,848 \cdot 4)$ & $\mathrm{ND}$ \\
Males aged 18 to 40y; $n=72$ & $30071(25056,37260)$ & $260 \cdot 4(176 \cdot 4,428 \cdot 4)$ & ND \\
Males aged 21 to 44 $; n=15$ & $25622(16398,29760)$ & $219 \cdot 2(94 \cdot 1,484 \cdot 0)$ & $29 \cdot 5(19 \cdot 9,56 \cdot 1)$ \\
Males aged 46 to 71 y; $n=20$ & $18458(13837,21362)$ & $297 \cdot 3(136 \cdot 0,384 \cdot 1)$ & $38 \cdot 8(28 \cdot 6,53 \cdot 9)$ \\
Males aged 55 to 75y; $n=24$ & $16729(11802,20681)$ & $579 \cdot 6(361 \cdot 2,1075 \cdot 2)$ & $32 \cdot 9(27 \cdot 0,45 \cdot 0)$ \\
Females aged 56 to 75y; $n=23$ & $18089(11532,20304)$ & $453 \cdot 6(226 \cdot 8,680 \cdot 4)$ & $27 \cdot 4(18 \cdot 6,38 \cdot 0)$ \\
\hline
\end{tabular}

Data are the median values observed in various studies carried out by the authors; values in parentheses indicate the 25 th and 75th centiles. tDetermined over the final $18 \mathrm{~h}$ of a $66 \mathrm{~h}$ period of culture of MNC in the presence of $15 \mu \mathrm{g} / \mathrm{ml}$ Con A. १Determined (by enzyme-linked immunosorbant assay) in the culture medium after $24 \mathrm{~h}$ of culture of MNC in the presence of $15 \mu \mathrm{g} / \mathrm{ml}$ Con A. *Determined as lactate dehydrogenase release from K562 target cells over $4 \mathrm{~h}$ at a MNC to K562 cell ratio of 100:1. ND indicates not determined. Data are previously unpublished in this form.

monocytes, macrophages, neutrophils and lymphocytes (Lee et al. 1985; Endres et al. 1989; Sperling et al. 1993; Gibney and Hunter, 1993; Caughey et al. 1996; Kelley et al. 1999; Yaqoob et al. 2000; Healy et al. 2000) (Table $3)$. In parallel with this there is a decrease in the ARA content of cell membranes (Table 3 ). This means that there is less substrate available for synthesis of eicosanoids from ARA. Furthermore, EPA competitively inhibits the metabolism of ARA. Thus, fish oil feeding results in a decreased capacity (by 40-75\%) of immune cells to synthesise eicosanoids from ARA (Lee et al. 1985; Endres et al. 1989; Meydani et al. 1993; Sperling et al. 1993;
Linoleic acid

$(18: 2 n-6)$

6-Desaturase

GLA

$(18: 3 n-6)$
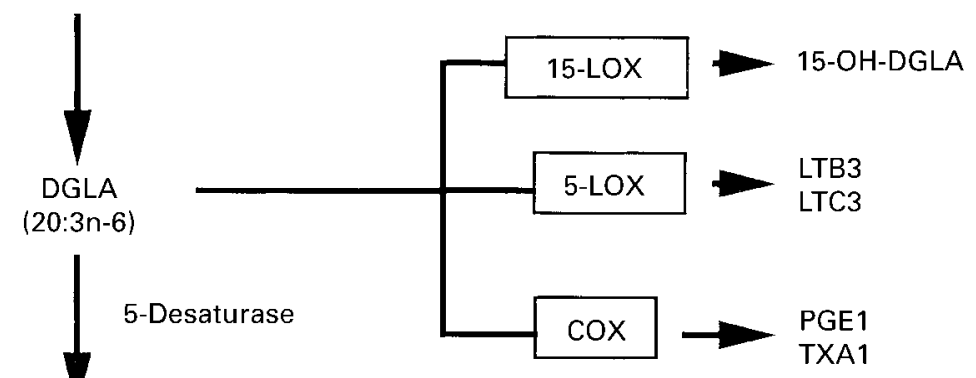

ARA

(20:4n-6)
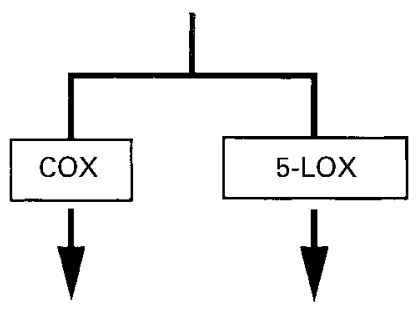

TXA2
LTB4

LTC4

LTD4

LTE4

5-HETE
Alpha-Linolenic acid (18:3n-3)

6-Desaturase

Stearidonic acid

(18:4n-3)
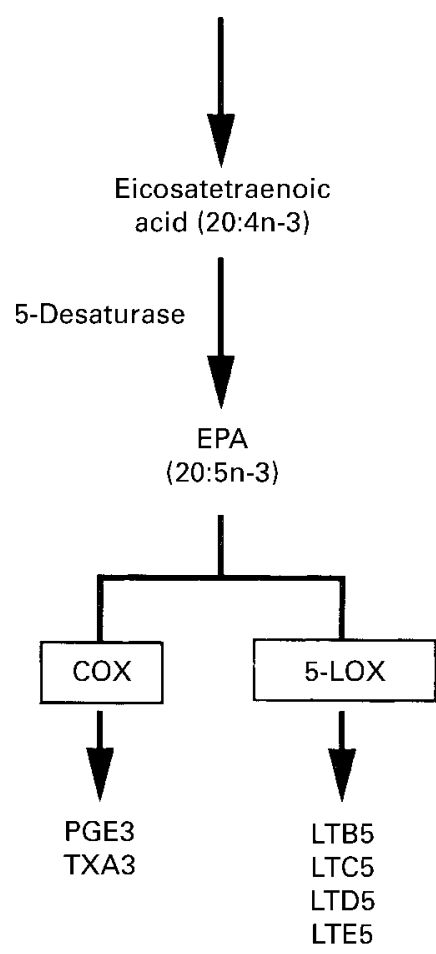

Fig. 3. Synthesis of eicosanoids from different precursor fatty acids. 
Table 3. Fatty acid composition of human mononuclear cells after supplementation of the diet with evening primrose oil or fish oil

\begin{tabular}{llllll}
\hline & \multicolumn{3}{c}{ Fatty acid $(\mathrm{g} / 100 \mathrm{~g}$ of total fatty acids) } \\
\cline { 2 - 3 } \cline { 5 - 6 } \cline { 5 - 6 } Fatty acid & \multicolumn{2}{c}{ Evening primrose oil } & & \multicolumn{2}{c}{ Fish oil } \\
\cline { 2 - 3 } \cline { 5 - 6 } & Before & \multicolumn{1}{c}{ After } & & Before & \multicolumn{1}{c}{ After } \\
\hline DGLA & $1.2(0.4)$ & $2.2(0.4)^{\star}$ & & $1.3(0.5)$ & $1.9(0.5)$ \\
ARA & $20.6(2.1)$ & $21.2(0.5)$ & & $22.3(0.8)$ & $18.8(1.3)^{*}$ \\
EPA & $1.0(0.3)$ & $1.1(0.4)$ & & $0.8(0.4)$ & $2.8(0.2)^{*}$ \\
DHA & $2.7(0.4)$ & $2.6(0.4)$ & & $1.9(0.5)$ & $3.3(0.3)$ \\
\hline
\end{tabular}

Healthy volunteers supplemented their diet with $9 \mathrm{~g}$ evening primrose oil (providing $1 \mathrm{~g}$ GLA) per day or with $9 \mathrm{~g}$ fish oil (providing $3.2 \mathrm{~g}$ EPA plus DHA) per day for 8 weeks. Mononuclear cells were isolated by standard techniques and the fatty acid composition determined. Data are mean (SEM) for six subjects per group and are taken from Yaqoob et al. (2000). *Indicates significantly different from before supplementation.

Caughey et al. 1996). A recent study reported that $6 \mathrm{~g} \mathrm{DHA}$ per day resulted in a $60 \%$ decrease in $\mathrm{PGE}_{2}$ production and a $75 \%$ decrease in $\mathrm{LTB}_{4}$ production (Kelley et al. 1999); whether this is due to DHA itself or due to retroconversion of DHA to EPA is not clear from the data provided. ALNA is the precursor of EPA. Caughey et al. (1996) reported that $13.7 \mathrm{~g}$ ALNA per day resulted in a $33 \%$ decrease in $e x$ vivo $\mathrm{PGE}_{2}$ production by human $\mathrm{MNC}$; this is most likely due to the conversion of ALNA to EPA. In addition to competitively inhibiting the metabolism of ARA to eicosanoids, EPA is able to act as a substrate for both COX and 5-LOX (Fig. 3), giving rise to derivatives which have a different structure from those produced from ARA (i.e. 3-series PG and 5-series LT). Thus, the EPA-induced suppression in the production of ARA-derived eicosanoids is believed to be mirrored by an elevation in the production of EPA-derived eicosanoids. Although this has been clearly demonstrated by Lee et al. (1985) and Sperling et al. (1993), who showed that dietary fish oil results in significantly increased generation of the 5-LOX products of EPA by stimulated neutrophils and monocytes, the production of 3-series PG by human cells after fish oil feeding has not been demonstrated. The eicosanoids produced from EPA are considered to be less biologically potent than the analogues synthesised from ARA, although the full range of biological activities of these compounds has not been investigated.

\section{Influence of the amount of fat in the diet on lymphocyte functions}

\section{Animal feeding studies}

Many studies have compared the effects of feeding laboratory animals low and high fat diets upon lymphocyte proliferation and NK cell activity (see Calder, 1998 $a$ for references). Such studies have often found that high fat diets result in diminished lymphocyte functions compared with low fat diets, but the precise effect depends upon the exact level of fat used in the high fat diet and its source. The DTH response was reduced after feeding high fat, compared with low fat, diets (Friend et al. 1980; Crevel et al. 1992). These data indicate that a high fat diet diminishes lymphocyte activities and the cell-mediated immune response.

\section{Human studies}

A reduction in total dietary fat intake (from $41 \%$ to $25 \%$ to $31 \%$ of total energy) enhanced blood lymphocyte proliferation in response to Con A or PHA by about $200 \%$ (Kelley et al. 1989, 1992). NK cell activity was increased by $50 \%$ by a reduction in fat intake from $30 \%$ to an average of $22 \%$ of total energy (Barone et al. 1989; Hebert et al. 1990). In these latter studies the reduction in fat intake was achieved without altering the fatty acid composition of the diet. These studies suggest that human lymphocyte responses can be enhanced by decreasing the amount of fat in the diet. In contrast, reducing fat intake of elderly Danish subjects from 40 to $29 \%$ energy did not affect NK cell activity (Rasmussen et al. 1994), although in this study the reduction in total fat intake was accompanied by an increased contribution of linoleic acid and of $n-3$ PUFA to dietary fat.

\section{Influence of the type of fatty acid in the diet on lymphocyte functions}

The influence of saturated fatty acids, oleic acid (18:1n-9), linoleic acid, ALNA, ARA and the long chain n-3 PUFA, EPA and DHA, on the functions of lymphocytes and antigen presenting cells, on cytokine production by these cells and on adhesion molecule expression and cell-cell interactions has been reviewed elsewhere in detail (Calder, 1995, $1996 a, b, 1997,1998 a, b, c)$. Thus, these effects will be summarised here; data from new studies and for fatty acids whose effects were not described previously will be described in detail.

\section{Saturated fatty acids}

In vitro and animal feeding studies suggest that saturated fatty acids have limited impact on lymphocyte proliferation, Th1-type and Th2-type cytokine production and NK cell activity (see Calder, 1995, 1996b, 1998a,c). The lack of effect of varying the intake of saturated fatty acids on NK cell activity is supported by human studies (Hebert et al. 1990; Rasmussen et al. 1994).

\section{Oleic acid}

In vitro and animal feeding studies show that oleic acid in sufficient amounts can partially inhibit lymphocyte proliferation, IL-2 production, IL-2 receptor and adhesion molecule expression and NK cell activity (see Calder, 1995, $1996 a, 1998 a, c)$. These observations suggest that dietary oleic acid has the potential to modulate lymphocyte functions, although the contribution of oleic acid to the animal diets in these studies was greatly in excess of the contribution to the diet of free living humans. Yaqoob et al. (2000) included a group who supplemented their habitual diet with an extra $9 \mathrm{~g}$ of olive oil/day for 12 weeks. This had no effect on lymphocyte proliferation, NK cell activity, or production of TNF- $\alpha$, IL- $1 \alpha$, IL- $1 \beta$, IL- 2 , or IFN- $\gamma$ by 
MNC. One study of the effect of dietary intervention with oleic acid upon human lymphocyte functions has been performed (Yaqoob et al. 1998). In this study healthy free living subjects increased their oleic acid intake from $11 \%$ to $18 \%$ of energy at the expense of saturated fatty acids. After two months there was a non-significant reduction in NK cell activity and lymphocyte proliferation, and the number of MNC expressing CD54 was significantly decreased (Yaqoob et al. 1998).

\section{Linoleic acid}

In vitro and animal feeding studies have shown that linoleic acid in sufficient amounts can partially inhibit lymphocyte proliferation, production of IL-2, CTL activity, NK cell activity and the production of IgG and IgM (see Calder, 1995, 1996a, 1998a,c). The DTH response was lower after feeding n-6 PUFA-rich diets compared with saturated fatrich or low fat diets. These observations suggest that high levels of linoleic acid in the diet impair the cell-mediated and antibody responses. However, more modest changes in the amount of linoleic acid in the rat diet did not markedly affect lymphocyte proliferation or NK cell activity (Jeffery et al. 1997).

Surprisingly few human studies have investigated the immunological impact of linoleic acid. The most detailed of the studies which have been performed are those of Kelley et al. (1989, 1992), which involved providing volunteers with low fat diets ( $25 \%$ energy as fat) which were rich in linoleic acid (12.9\% of energy) or poor in linoleic acid (3.5\% of energy). No differences were observed in the responses of lymphocytes to various T-cell mitogens, in circulating $\operatorname{IgM}, \operatorname{IgG}, \operatorname{IgE}$ or IgA levels, or in the DTH response to seven recall antigens. Yaqoob et al. (2000) included a group who supplemented their habitual diet with an extra $9 \mathrm{~g}$ of sunflower oil/day for 12 weeks. This had no effect on lymphocyte proliferation, NK cell activity, or production of TNF- $\alpha$, IL- $1 \alpha$, IL- $1 \beta$, IL- 2 , or IFN- $\gamma$ by MNC. These studies suggest limited impact of linoleic acid (at levels between 3.5 and $12.9 \%$ of dietary energy) upon human immune function. However, in another study, the low fat diet induced increase in human NK cell activity (Barone et al. 1989; Hebert et al. 1990) was reversed by adding $15 \mathrm{~g}$ safflower oil/day to the diet for 2 months (Hebert et al. 1990); in this study linoleic acid contributed about $8.2 \%$ of dietary energy when the subjects were consuming the safflower oil supplement. Furthermore, the NK cell activity of blood lymphocytes from elderly Danish subjects correlated negatively with linoleic acid intake and with serum levels of linoleic acid (Rasmussen et al. 1994); unfortunately this paper does not provide the data for linoleic acid intakes among the subjects.

\section{Conjugated linoleic acid}

Cook et al. (1993) reported that including conjugated linoleic acid (CLA) in the diet of chickens ( $0.5 \mathrm{~g} / 100 \mathrm{~g}$ diet $)$ increased lymphocyte proliferation in response to T-cell mitogens. More recent studies have reported some immunological effects of feeding a mixture of isomers of CLA to laboratory rodents. These studies have employed a fairly low fat diet (5\% fat by weight) in which CLA comprised $20 \%$ of fatty acids present. Feeding this diet to mice increased lymphocyte proliferation and IL-2 production but did not affect NK cell activity (Hayek et al. 1999), while feeding it to rats decreased TNF- $\alpha$ and IL-6 production by macrophages (Turek et al. 1998). It is unclear which CLA isomers are responsible for these effects. At the time of writing no studies of the influence of CLA on human immune function have been published.

\section{$\gamma$-Linolenic and di-homo- $\gamma$-linolenic acids}

Both GLA and DGLA inhibited proliferation of cultured human lymphocytes (Kelley \& Parker, 1979; Santoli et al. 1990; deMarco et al. 1994; Purasiri et al. 1997; Zurier et al. 1999), and DGLA decreased the production of IL-2 by human lymphocytes (Santoli et al. 1990); GLA probably also decreases IL-2 production but this has not been studied. GLA and DGLA inhibited production of IL-1 $\beta$ and of TNF- $\alpha$ by human monocytes in culture (DeLuca et al. 1999). Human peripheral blood NK cell activity was decreased after culture of the cells with GLA (Purasiri et al. 1997).

Feeding rats oils rich in GLA (e.g. evening primrose oil) decreased lymphocyte proliferation and NK cell activity, and decreased the expression of the IL-2 receptor and of some adhesion molecules (CD2, CD11a, CD18, CD54, CD62L) on the surface of lymphocytes (Yaqoob et al. 1994a,b; Sanderson et al. 1995a,b; Sanderson \& Calder, 1998; Peterson et al. 1999). These observations suggest that GLA in sufficient quantities will diminish the Th1-type response. This is confirmed by the work of Matsuo et al. (1996) who showed that evening primrose oil increased total and ovalbumin-specific IgE production by spleen lymphocytes and increased circulating total and ovalbumin-specific IgE levels following ovalbumin challenge to ovalbuminsensitised Brown Norway rats. In contrast, evening primrose oil suppressed ovalbumin-specific IgG production by lymphocytes, although circulating total and ovalbuminspecific IgG levels were unaffected by diet. Thus, it appears that GLA acts to diminish the Th1-type lymphocyte response.

Supplementation studies using GLA-rich oils to provide $\geq 2.4 \mathrm{~g}$ GLA per day in healthy human volunteers report decreased production of TNF- $\alpha$, IL-1 and IL-6 by monocytes (Watson et al. 1993; DeLuca et al. 1999), and decreased lymphocyte proliferation (Rossetti et al. 1997). Recent studies providing $\leq 1 \mathrm{~g}$ GLA report no effect on lymphocyte proliferation (Yaqoob et al. 2000), NK cell activity (Yaqoob et al. 2000; Thies et al. 2001a) or production of TNF- $\alpha$, IL-1 $\beta$, IL-2 or IFN- $\gamma$ (Wu et al. 1999; Yaqoob et al. 2000; Thies et al. 2001b,c). These observations suggest that a GLA intake of somewhere between 1 and $2.4 \mathrm{~g}$ per day is required to exert immunological effects in healthy humans.

\section{Arachidonic acid}

ARA increased IL-1 $\beta$ production by cultured human monocytes (Baldie et al. 1993). In contrast, ARA inhibited the proliferation of cultured lymphocytes, decreased the 
production of IL-2, and inhibited CTL degranulation (see Calder, 1995, 1996a, 1998c). Feeding rats or mice on diets containing significant amounts of ARA did not affect spleen lymphocyte proliferation, IL-2 production, NK cell activity or the graft versus host response, despite the increased capacity of the cells to produce $\mathrm{PGE}_{2}$ (Jolly et al. 1997; Peterson et al. 1998a). These studies suggest that even significant amounts of ARA in the rodent diet do not influence cell-mediated immunity.

Two studies of the influence of dietary ARA upon human immune function have been performed. Including ARA ( $1.5 \mathrm{~g}$ per day) as part of a low fat diet ( $27 \%$ energy as fat) for 8 weeks did not alter the proliferation of lymphocytes, NK cell activity, the DTH response to seven recall antigens, TNF- $\alpha$, IL-1 $\beta$, IL- 6 or IL-2 production by MNC or the in vivo antibody responses to immunisation with three strains of influenza virus (Kelley et al. 1997, 1998a). ARA did however increase production of $\mathrm{PGE}_{2}$ and $\mathrm{LTB}_{4}$ by LPSstimulated MNC. Supplementing the diet of healthy subjects aged 55 to 75 years with encapsulated ARA (approximately $700 \mathrm{mg} /$ day) for 12 weeks did not effect the NK cell activity, lymphocyte proliferation or the production of TNF- $\alpha$, IL$1 \beta$, IL-6, IL-2 or IFN- $\gamma$ by MNC (Thies et al. 2001a,b,c). Although these studies suggest that increasing ARA consumption in healthy adults does not have adverse immunological effects, the length of ARA administration in these studies was no more than 12 weeks and the immunological effects of ARA over a longer term are not known.

\section{$\alpha$-Linolenic acid}

In vitro and animal feeding studies indicated that ALNA inhibits lymphocyte proliferation, the production of IL-2, CTL activity, NK cell activity and the graft versus host response (see Calder 1995, 1996a,b, 1998a,c). The precise effect of ALNA on lymphocyte functions appears to depend on the level of linoleic acid and the total PUFA content of the diet (Jeffery et al. 1997).

A high dose of ALNA in the human diet (approximately $13 \mathrm{~g}$ per day for 4 weeks) decreased IL-1 and TNF production by LPS-stimulated monocytes (Caughey et al. 1996). Adding linseed oil (providing about $15 \mathrm{~g}$ ALNA per day) to a low fat diet (29\% energy from fat) resulted in a significant decrease in human blood lymphocyte proliferation and in the DTH response to seven recall antigens after 6 weeks, but circulating antibody levels were unaffected (Kelley et al. 1991). Supplementing the diet of healthy subjects aged 55 to 75 years with linseed oil providing $2 \mathrm{~g}$ ALNA per day did not significantly affect NK cell activity, lymphocyte proliferation or production of TNF- $\alpha$, IL-1 $\beta$, IL-6, IL-2 or IFN- $\gamma$ by MNC (Thies et al. 2001a,b,c). These studies suggest that a moderate increase in ALNA intake by healthy adults does not affect immunity, but that a marked increase in ALNA intake can induce immunomodulatory effects. It is not clear whether these are exerted by ALNA itself or by EPA, a product of ALNA metabolism.

\section{Eicosapentaenoic and docosahexaenoic acids}

Since dietary fish oil leads to decreased $\mathrm{PGE}_{2}$ production, it is often stated that it should reverse the effects of $\mathrm{PGE}_{2}$, simply acting as a $\mathrm{PGE}_{2}$ antagonist. If this were so then fish oil should increase the production of the classic pro-inflammatory cytokines (TNF, IL-1 and IL-6), increase the production of Th1-type cytokines, enhance MHC II expression, lymphocyte proliferation and NK cell activity and decrease $\operatorname{IgE}$ production by B-lymphocytes. Many studies, especially those conducted in laboratory animals, have demonstrated that, while in some situations fish oil does act as a 'PGE 2 antagonist', it often induces effects which are the opposite to those predicted on this basis. Thus, the situation is more complex than fish oil simply being a $\mathrm{PGE}_{2}$ antagonist. This is because $\mathrm{PGE}_{2}$ is not the sole mediator produced from ARA, and the range of mediators produced has varying, sometimes opposite, actions (see earlier). Thus, if fish oil was to act as a '4-series LT antagonist' it would be expected to decrease production of pro-inflammatory and Th1-type cytokines, and NK cell activity. EPA itself will give rise to eicosanoids with varying actions, some augmenting the actions of ARA-dereived mediators and others antagonising those actions. In addition long chain $n$-3 PUFA may exert a range of eicosanoid-independent effects, especially upon intracellular signalling mechanisms. Thus, the overall effect of fish oil feeding cannot be predicted solely on the basis of an abrogation of $\mathrm{PGE}_{2}$-mediated effects.

In vitro studies have revealed a marked influence of long chain $n$-3 PUFA on inflammatory and immune cell function. EPA and DHA inhibited cytokine-induced cell surface expression of MHC II on macrophages and monocytes (Khair-el-Din et al. 1995; Hughes et al. 1996a), and decreased the ability of human monocytes to present antigen (tetanus toxoid) to autologous lymphocytes (Hughes \& Pinder, 1997). In culture, EPA and DHA inhibit the production of IL-1 $\beta$, TNF- $\alpha$, IL- 6 and IL-2, the proliferation of lymphocytes, and NK cell activity (see Calder 1995, 1996a,b, 1997, 1998a,b,c).

Feeding fish oil to laboratory rodents decreased MHC II expression and diminished presentation of antigen ex vivo (see Calder, 1996a,b, 1998a,b,c). A recent study reported that dietary fish oil decreased expression of the IFN- $\gamma$ receptor on murine macrophages and splenocytes (Feng et al. 1999). Fish oil feeding has been reported to decrease ex vivo production of TNF- $\alpha$, IL- $1 \beta$ and IL- 6 by rodent inflammatory macrophages and monocytes (see Calder, $1996 a, b, 1997,1998 b)$. These studies suggest that dietary fish oil might diminish the cell-mediated immune response by decreasing the activity of antigen presenting cells and by decreasing the sensitivity of macrophages to T-lymphocytederived cytokines. High levels of dietary fish oil decrease NK cell activity, CTL activity, lymphocyte proliferation, expression of the IL-2 receptor and adhesion molecules on lymphocytes (see Calder, 1995, 1996a,b, 1998a,c) and the production of IL-2 (Jolly et al. 1997; Wallace et al. 2001) and IFN- $\gamma$ (Byleveld et al. 1999; Wallace et al. 2001). Dietary fish oil decreased the DTH and graft versus host responses compared with low fat or $n$-6 PUFA-rich or olive oil-rich diets (see Calder, 1995, 1996a,b, 1998a,c). Dietary fish oil also prolonged the survival of skin, kidney, heart or Islets of Langerhans transplants in rodents (see Calder, $1996 a, b, 1998 a, c)$. Taken together, these studies suggest 
that fish oil induces a shift in the T-lymphocyte response away from the Th1-type response, which is involved in cellmediated immunity, chronic inflammation and graft rejection. In accordance with this, fish oil enhanced production of $\operatorname{IgE}$ to ovalbumin in rats (Prickett et al. 1982). Animal studies have often used very large amounts of fish oil in the diet: a diet in which fish oil contributes $20 \%$ by weight will mean that EPA plus DHA comprise up to $30 \%$ of dietary fatty acids and up to $12 \%$ of dietary energy. Recent studies in rats and mice have indicated that relatively low levels of the long chain $n-3$ fatty acids (EPA or DHA at a level of $4.4 \%$ of total fatty acids or $1.7 \%$ of dietary energy) are sufficient to bring about some of the effects of fish oil, that dietary EPA and DHA both inhibit lymphocyte proliferation and IL-2 production and that dietary EPA, but not DHA, inhibits NK cell activity (Jolly et al. 1997; Peterson et al. 1998a,b).

Supplementation of the diet of human volunteers with $1.6 \mathrm{~g}$ EPA plus DHA per day for 3 weeks resulted in decreased expression of MHC II (HLA-DP, -DQ and -DR) and of CD54 on the surface of blood monocytes (Hughes et al. 1996b). Fish oil providing more than $2.4 \mathrm{~g}$ EPA plus DHA per day decreased production of TNF, IL-1 and IL- 6 by MNC (Endres et al. 1989; Meydani et al. 1991; Gallai et al. 1993; Caughey et al. 1996). One other study in which subjects consumed a low fat diet including oily fish daily (providing 1.2 g EPA plus DHA per day) showed decreased production of TNF, IL-1 and IL-6 (Meydani et al. 1993). In contrast to these observations, a number of studies which provided from $0.55 \mathrm{~g}$ to $3.4 \mathrm{~g}$ EPA plus DHA per day have failed to demonstrate an effect of fish oil on production of TNF, IL-1 and IL-6 (Molvig et al. 1991; Cooper et al. 1993; Cannon et al. 1995; Schmidt et al. 1996; Blok et al. 1997; Yaqoob et al. 2000; Thies et al. 2001c). Data from studies investigating the influence of fish oil on human lymphocyte functions are also conflicting. Supplementation of the diet of healthy human volunteers with fish oil providing $2.4 \mathrm{~g}$ EPA plus DHA per day resulted in decreased proliferation of lymphocytes from older (aged 51-68 years) but not young (aged 21-33 years) women and decreased IL-2 production (Meydani et al. 1991). Molvig et al. (1991) reported decreased lymphocyte proliferation after providing 1.7 or $3.4 \mathrm{~g}$ EPA plus DHA per day to men, while Gallai et al. (1993) reported that 5.2 g EPA plus DHA per day decreased IL- 2 and IFN- $\gamma$ production. Providing $1 \cdot 2 \mathrm{~g}$ EPA plus DHA to healthy subjects aged 55-75 years resulted in decreased NK cell activity (Thies et al. 2001a) and lymphocyte proliferation (Thies et al. 2001b), but did not affect IL-2 or IFN- $\gamma$ production (Thies et al. 2001b). Finally, inclusion of oily fish providing $1.2 \mathrm{~g}$ EPA plus DHA per day in the diet of volunteers consuming a low fat diet decreased lymphocyte proliferation, IL-2 production and the DTH response to seven recall antigens (Meydani et al. 1993). In contrast to these observations, there are reports of no effect of $3 \cdot 2 \mathrm{~g}$ EPA plus DHA per day on NK cell activity, lymphocyte proliferation and IL-2 and IFN- $\gamma$ production (Yaqoob et al. 2000) and of no effect of $4.6 \mathrm{~g} \mathrm{EPA}$ plus DHA per day on lymphocyte proliferation and IL-2 production (Endres et al. 1993). Thus, several studies indicate that a high level of dietary fish oil can inhibit monocyte and lymphocyte responses. Other studies indicate that more modest addition of fish oil to the diet does not affect these responses. However, there are a large number of studies which fall between the extremes of 'modest addition' and 'high level' and these studies provide conflicting results. It is unclear what the reasons for these discrepancies are, but they might be related to different experimental protocols used, particularly those involving cell preparation, cell culture and cytokine assays and/or to different subject characteristics (e.g. gender, age, habitual diet).

Some recent studies in humans have examined whether the effects of fish oil are due to EPA or DHA. Kelley et al. $(1998 b, 1999)$ reported the effects in males aged 20-40 years of including $6 \mathrm{~g}$ DHA per day in a low fat diet $30 \%$ energy as fat) for 90 days. There was no effect of DHA on lymphocyte proliferation, serum IgG concentration or the DTH response to seven recall antigens or on the serum antibody response to immunisation with three strains of influenza virus. NK cell activity was unaffected at day 55 but was decreased at day 90 . The production of TNF- $\alpha$ and IL-1 $\beta$ tended to decrease at day 55 but was significantly decreased at day 80. More recently, $750 \mathrm{mg}$ DHA per day was shown not to affect NK cell activity, lymphocyte proliferation or the production of TNF- $\alpha$, IL-1 $\beta$, IL-6, IL-2 or IFN- $\gamma$ in healthy subjects aged $55-75$ years (Thies et al. $2001 a, b, c)$. Taken together these data indicate that high levels of DHA (e.g. $6 \mathrm{~g}$ per day) can mimic some of the effects of fish oil but that lower levels (e.g. $<1 \mathrm{~g}$ per day) do not exert any immunological effects in healthy adults.

\section{Summary of the effects of fatty acids on lymphocyte functions}

It is apparent that lowering the amount of fat consumed in the diet will enhance lymphocyte responses, although a supply of essential fatty acids is necessary to support the development of lymphoid organs and the responsiveness of lymphocytes. It is also apparent that at any particular level of fat in the diet, varying the fatty acid composition may impact on lymphocytes. In vitro and animal feeding studies suggest that saturated fatty acids have a limited effect on immune function, but that unsaturated fatty acids have the capacity to modulate lymphocyte functions and the cellmediated and antibody responses to challenge. Among the unsaturated fatty acids, PUFA appear particularly potent with GLA, DGLA, ARA, EPA and DHA all exerting fairly similar effects in vitro upon lymphocyte proliferation, IL-2 production, and NK and CTL activities. Animal feeding studies indicate that a high intake of oleic acid, linoleic acid, GLA, ALNA, EPA or DHA can influence lymphocyte function and cell-mediated immunity. The intakes of these fatty acids used in animal studies are often greatly in excess of those which could be achieved in free living humans, and it appears from human studies that reasonable variation in intakes of oleic acid, linoleic acid and ALNA probably has limited impact on immune function. However, large longterm differences in habitual intakes of these fatty acids might influence immune function, and affect the incidence of diseases that have an immunological component (e.g. Linos et al. 1991). It is the PUFA which are habitually consumed in small amounts (GLA, EPA, DHA) which appear to have the more potent immunological effects. The studies performed to date have not clearly defined the doseresponse effects for these fatty acids. However, it appears 
that the levels at which these fatty acids will influence lymphocyte functions can be achieved only through consumption of the pure oils. The immunological effects of GLA and of the long chain $n$-3 PUFA are generally termed as anti-inflammatory and the applications of these effects have been described in terms of chronic inflammatory diseases, allergic inflammation, acute systemic inflammation in response to trauma and graft rejection.

\section{Applications}

\section{Chronic inflammatory diseases}

Chronic inflammatory diseases are characterised by a dysregulated, overactive Th1-type response and often by an inappropriate production of ARA-derived eicosanoids, especially $\mathrm{PGE}_{2}$ and $\mathrm{LTB}_{4}$. The effects of fish oil outlined above suggest that it might have a role in prevention and therapy of these diseases (Fig. 4). Dietary fish oil has been shown to have beneficial clinical, immunological and biochemical effects in various animal models of human chronic inflammatory diseases, including decreased incidence and severity of inflammation in mice with type II collagen-induced arthritis (Leslie et al. 1985) and less inflammation in rat models of colitis (Wallace et al. 1989; Vilaseca et al. 1990). It was recently reported that both EPA and DHA suppress streptococcal cell wall-induced arthritis in rats, but that EPA was more effective (Volker et al.

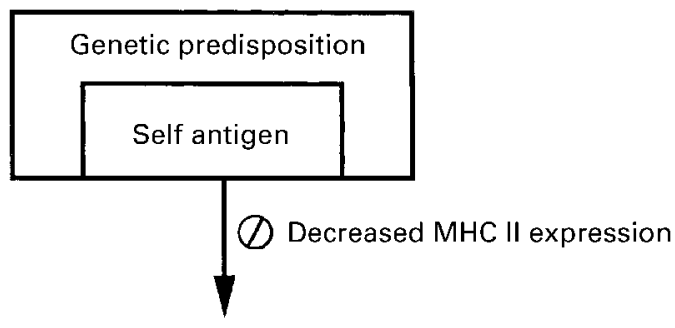

Antigen presenting cells (e.g. macrophages)

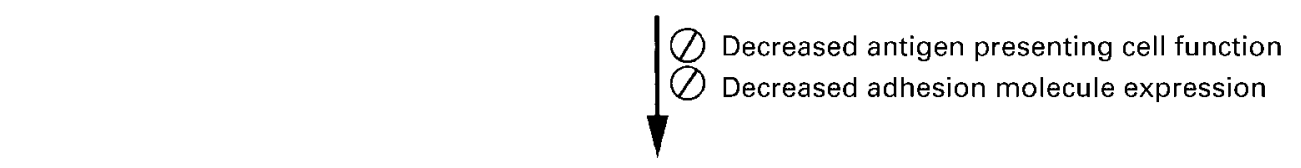

Th1 lymphocytes $\oslash$ Decreased T cell proliferation

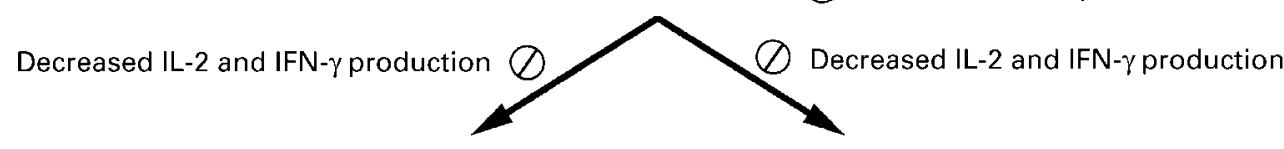

B lymphocytes

Macrophages
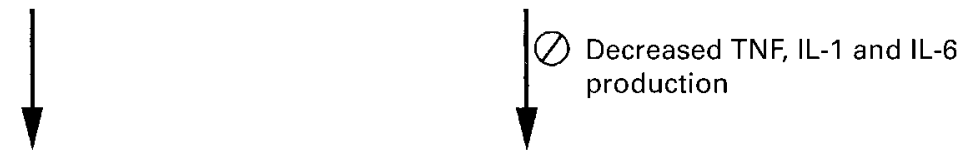

Auto-antibodies

Pro-inflammatory cytokines
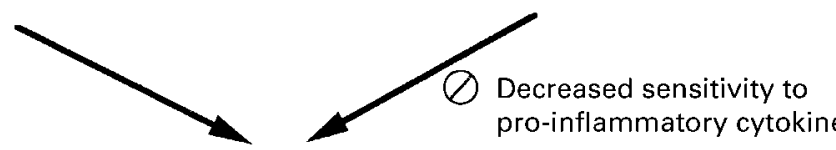

Chronic inflammation

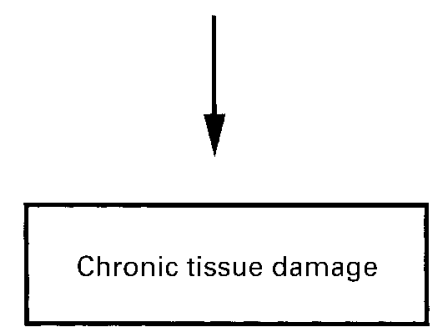

Fig. 4. Potential sites of action of $n-3$ PUFA in ameliorating chronic inflammatory diseases. Chronic inflammatory diseases are characterised by a dysregulated Th1 response resulting from inappropriate recognition of self-antigen in genetically predisposed individuals. $n-3$ PUFA can exert anti-inflammatory effects at several points (Ø) to induce clinical benefit. 
Table 4. Summary of clinical trials of fish oil in chronic inflammatory diseases

\begin{tabular}{|c|c|c|c|c|c|}
\hline Disease & $\begin{array}{l}\text { Number } \\
\text { of } \\
\text { double- } \\
\text { blind, } \\
\text { placebo- } \\
\text { controlled } \\
\text { studies }\end{array}$ & $\begin{array}{c}\text { Doses of EPA } \\
+ \text { DHA used } \\
\text { (g/day) }\end{array}$ & $\begin{array}{l}\text { Duration } \\
\text { (weeks) }\end{array}$ & Key findings & Reviews \\
\hline $\begin{array}{l}\text { Rheumatoid } \\
\text { arthritis }\end{array}$ & 13 & $1-6 \cdot 4$ & $12-52$ & $\begin{array}{l}\text { All studies reported improvements, including reduced } \\
\text { duration of morning stiffness, reduced number of ten- } \\
\text { der or swollen joints, reduced joint pain, reduced time } \\
\text { to fatigue, and increased grip strength. } \\
\text { Twelve studies reported improvement in at least two } \\
\text { clinical measures, and five studies reported improve- } \\
\text { ment in at least four clinical measures. } \\
\text { Ten studies reported decreased joint tenderness. } \\
\text { Three studies reported significant decrease in the use } \\
\text { of non-steroidal anti-inflammatory drugs. }\end{array}$ & $\begin{array}{l}\text { James \& Cleland, 1997; } \\
\text { Geusens, 1998; Calder, } \\
2001\end{array}$ \\
\hline $\begin{array}{l}\text { Crohn's } \\
\text { Disease }\end{array}$ & 3 & $2 \cdot 7-5 \cdot 1$ & $12-52$ & $\begin{array}{l}\text { Two studies reported no benefit. } \\
\text { One study reported a significiant decrease in relapses. } \\
\text { One other study which used oily fish }(100-250 \mathrm{~g} / \text { day } \\
\text { for } 2 \text { years) reported a significant decrease in } \\
\text { relapses. }\end{array}$ & Belluzzi \& Miglio, 1998 \\
\hline $\begin{array}{l}\text { Ulcerative } \\
\text { colitis }\end{array}$ & 4 & $1 \cdot 8-5 \cdot 4$ & $12-52$ & $\begin{array}{l}\text { One study reported no benefit (this study used the } \\
\text { lowest dose of EPA plus DHA) } \\
\text { One study reported a non-significant decrease in dis- } \\
\text { ease activity and a significant decrease in use of corti- } \\
\text { costeroids. } \\
\text { Two studies reported benefit including improved histo- } \\
\text { logical appearance of the colon, decreased disease } \\
\text { activity, weight gain and decreased use of predniso- } \\
\text { lone. } \\
\text { Two other open studies reported improved symptoms, } \\
\text { improved histological appearance of the rectal } \\
\text { mucosa and decreased use of prednisolone. }\end{array}$ & Rodgers, 1998 \\
\hline Psoriasis & 2 & $1 \cdot 8$ & $8-12$ & $\begin{array}{l}\text { One study reported significant improvement in itching, } \\
\text { scaling and erythema. } \\
\text { One study reported no benefit. } \\
\text { Three open studies (providing } 10 \text { to } 18 \mathrm{~g} \text { EPA plus } \\
\text { DHA per day for } 6-8 \text { weeks) reported mild to moder- } \\
\text { ate (two studies) or moderate to excellent (one study) } \\
\text { improvements in scaling, itching, lesion thickness and } \\
\text { erythema in the majority of patients. }\end{array}$ & Ziboh, 1998 \\
\hline
\end{tabular}

2000); this fits with the more potent effects of EPA than DHA on inflammation and immunity.

There have been a number of clinical trials assessing the benefits of dietary supplementation with fish oil in several inflammatory diseases in humans including rheumatoid arthritis, Crohn's Disease, ulcerative colitis, and psoriasis (see Table 4 for a summary). Many of the placebocontrolled, double-blind trials of fish oil in chronic inflammatory diseases reveal significant benefit including decreased disease activity and a lowered use of antiinflammatory drugs; the evidence for a beneficial effect of fish oil is strongest in rheumatoid arthritis (Table 4).

\section{Asthma}

ARA-derived eicosanoids such as $\mathrm{PGD}_{2}, \mathrm{LTC}_{4}, \mathrm{D}_{4}$ and $\mathrm{E}_{4}$ are among the major mediators of allergic inflammation (Fig. 5). Although its action as a precursor to LT has highlighted the significance of ARA in the aetiology of allergic inflammation, a second link with this fatty acid has been made. This is because $\mathrm{PGE}_{2}$ regulates the differentiation and functions of lymphocytes (see earlier). Of particular relevance in the context of asthma and related IgE-mediated allergic diseases is the ability of $\mathrm{PGE}_{2}$ to inhibit the production of the Th1-type cytokine IFN- $\gamma$ without affecting the production of the Th2-type cytokines, and to stimulate B-cells to produce IgE. These observations suggest that $\mathrm{PGE}_{2}$ regulates the development of these diseases (Fig. 5). As a result of this there has been speculation that the increased intake of linoleic acid, the precursor of ARA, which has occurred since the mid-1960s, is causally linked to the increased incidence of asthma and allergic diseases over this period (Hodge et al. 1994; Black $\&$ Sharpe, 1997). Thus, a case has been made for increasing the consumption of $n-3$ fatty acids by patients with IgEmediated allergic diseases (Fig. 5). There is some epidemiological evidence to support a protective role of long chain $n$-3 PUFA in these diseases (see Calder \& Miles, 2000 for references). However, several studies of fish oil supplementation in asthma reveal limited clinical impact, 
despite significant biochemical changes (e.g. reduced 4-series LT production) (see Calder \& Miles, 2000 for references). In contrast, some studies have shown significant clinical improvements, at least in some patient groups, and suggest that this type of approach may be useful in conjunction with other drug- and diet-based therapies (see Calder \& Miles, 2000 for references). A very careful study by Broughton et al. (1997) found that low $n$-3 PUFA ingestion resulted in increased methacholine-induced respiratory distress in adult asthmatics (Table 5). In contrast, high $n-3$ PUFA ingestion resulted in an improved response in more than $40 \%$ of the subjects (Table 5); all measures of respiratory function were markedly improved in this group of patients who also showed elevated appearance of the EPA-derived 5-series LT in their urine. However, some patients did not respond to the high $n-3$ PUFA intake (Table 5). This study indicates that there are patients who respond positively to fish oil intervention and patients who are non-responders. This suggests that such therapies should be approached cautiously until more is understood about the interaction between fatty acid consumption and disease activity.

\section{Concluding remarks}

Amongst the fatty acids it is the $n-3$ PUFA which possess the most potent immunomodulatory activities, and amongst the $n-3$ PUFA those from fish oil (EPA and DHA) are more biologically potent than ALNA. Components of both natural and acquired immunity, including the production of key inflammatory mediators, can be affected by $n-3$ PUFA. Animal studies indicate that diets rich in EPA plus DHA are anti-inflammatory and immunomodulatory in vivo, although there have been relatively few good studies in humans. Although some of the effects of $n-3$ PUFA may be brought about by modulation of the amount and types of eicosanoids made, it is possible that these fatty acids might elicit some of their effects by eicosanoid-independent mechanisms,

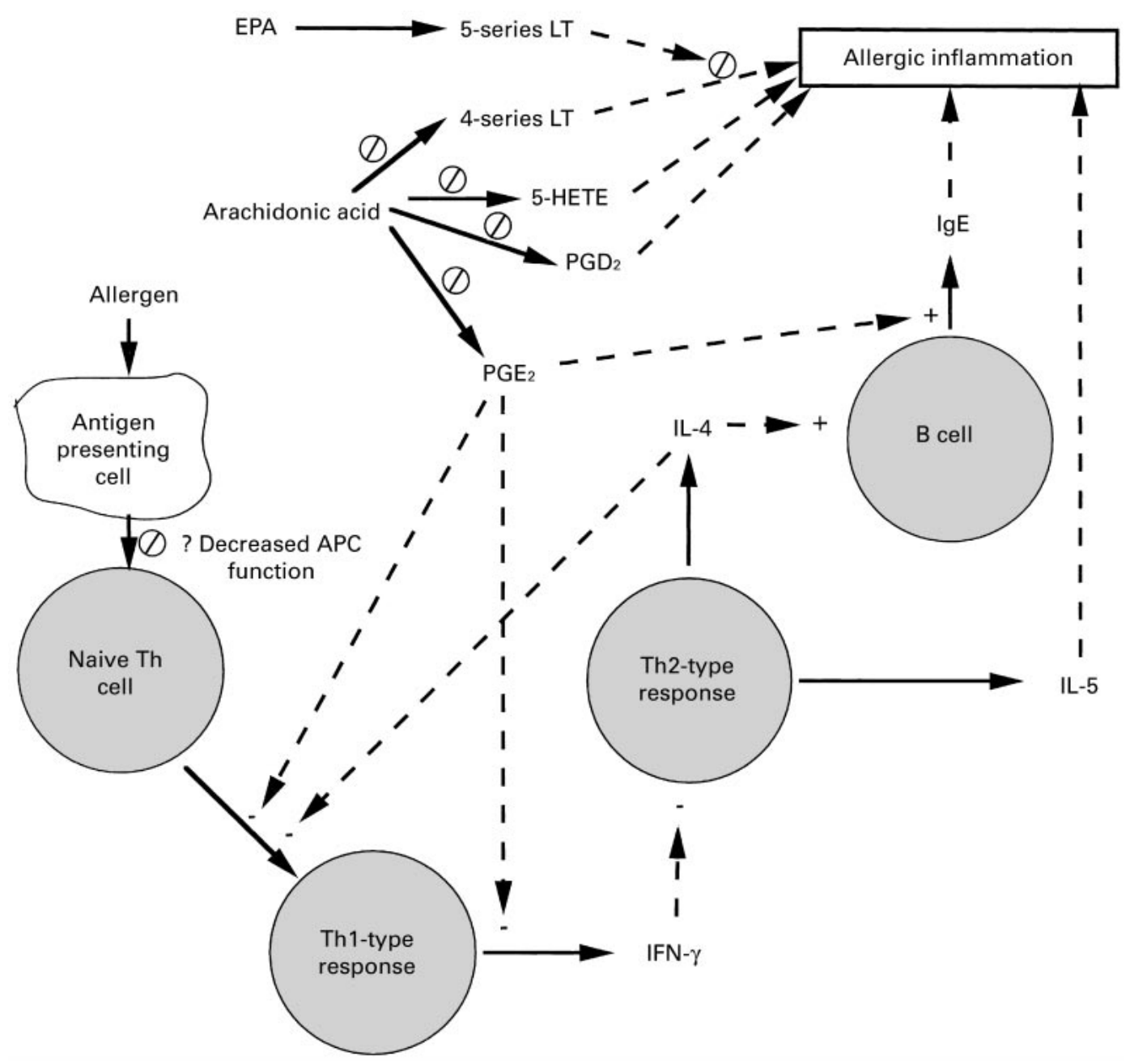

Fig. 5. Potential sites of action of $n-3$ PUFA in ameliorating IgE-mediated allergic diseases. ARA gives rise to mediators of allergic inflammation and $\mathrm{PGE}_{2}$ inhibits the development of the Th1 phenotype and the production of IFN- $\gamma$. This allows the development of the Th2 phenotype, with production of IL-4. IL-4 acts to reinforce the inhibition of the Th1-type response and also promotes IgE production by $\mathrm{B}$ cells. PGE ${ }_{2}$ acts directly on B-cells to promote IgE production. IL-5 is a mediator of allergic inflammation, while IL-10 (produced by Th2-type lymphocytes) inhibits development of the Th1-type response (not shown). $n$-3 PUFA can exert anti-inflammatory effects at several points (Ø) to induce clinical benefit. $\rightarrow$ indicates produces; --.- indicates regulates. 
Table 5. Influence of fish oil intervention in adult asthma

\begin{tabular}{|c|c|c|c|c|}
\hline & \multicolumn{4}{|c|}{ Cumalitive dose of methacholine to cause a $20 \%$ decline (units) } \\
\hline & \multirow{2}{*}{$\frac{\text { Baseline }}{(n=19)}$} & \multirow{2}{*}{$\frac{\text { Low dose fish oil }}{(n=19)}$} & \multicolumn{2}{|c|}{ High dose fish oil } \\
\hline & & & Responders $(n=9)$ & Non-responders $(n=10)$ \\
\hline Forced vital capacity & $24 \cdot 1$ & 11.8 & $>100$ & 3.7 \\
\hline Peak expiratory flow & $17 \cdot 1$ & 5.9 & $>100$ & 3.5 \\
\hline Forced expiratory volume/sec & $16 \cdot 9$ & 1.9 & $>100$ & 4.9 \\
\hline Forced expiratory flow $25-75 \%$ & $9 \cdot 0$ & 0.7 & $>100$ & $9 \cdot 9$ \\
\hline
\end{tabular}

Adult asthmatics consumed fish oil capsules for 4 weeks such that the $n-6$ to $n$-3 PUFA ratio of their diet was 10 (low dose fish oil) or 2 (high dose fish oil). At baseline, after consuming the low dose fish oil and after consuming the high dose fish oil subjects underwent challenge with increasing amounts of methacholine to give cumulative doses up to 68 units. Data are the cumulative dose of methacholine required to cause a $20 \%$ reduction in each indicator of lung function. Data are from Broughton et al. (1997).

including actions upon intracellular signalling pathways and transcription factor activity (see Miles \& Calder, 1998; Yaqoob, 1998b). Such $n$-3 PUFA-induced effects may be of use as a therapy for chronic inflammatory conditions characterised by an overactive Th1 response, and for disorders like asthma characterised by an overactive Th2 response. Moderate levels of ARA and DHA do not appear to have any significant effects on human immune function, but the effects of these fatty acids have been studied in the short term and only in healthy adults. All studies of fatty acids and the human immune system have used adults as subjects and most studies have used men only or a mixture of men and women. The only study which has used women exclusively as subjects was that of Meydani et al. (1991); in that study it was found that the immune system of older women is more sensitive to fish oil than is that of young women. This age-related difference in sensitivity to dietary intervention may explain some of the contradictory observations in the literature (e.g. between Yaqoob et al. 2000 and Thies et al. 2001a,b). It is clear that more needs to be understood about the impact of $n-6$ and $n-3$ PUFA on the human immune system and on how variations in age, gender, ethnicity, hormone status, antioxidant status and genetics influence sensitivity to dietary PUFA.

\section{Acknowledgements}

Data shown in Tables 1 and 2 are from studies funded by grants from the Ministry of Agriculture, Fisheries \& Foods (Grant Nos. ANO215 and AFQ51), the Biotechnology \& Biological Sciences Research Council (Grant No. 51/D05696) and the Nutricia Research Foundation.

\section{References}

Alexander JW (1998) Immunonutrition: The role of $\omega-3$ fatty acids. Nutrition 14, 627-633.

Baldie G, Kaimakamis D \& Rotondo D (1993) Fatty acid modulation of cytokine release from human monocytic cells. Biochimica et Biophysica Acta 1179, 125-133.

Barone J, Hebert JR \& Reddy MM (1989) Dietary fat and natural killer cell activity. American Journal of Clinical Nutrition 50, 861-867.

Belluzzi A \& Miglio F (1998) n-3 Fatty acids in the treatment of Crohn's Disease. In Medicinal Fatty Acids in Inflammation, pp. 91-101 [J Kremer, editor]. Basel: Birkhauser Verlag.
Black PN \& Sharp S (1997) Dietary fat and asthma: is there a connection? European Respiratory Journal 10, 6-12.

Blok WL, Deslypere J-P, Demacker PNM, van der Ven-Jongekrijg J, Hectors MPC, van der Meer JMW \& Katan MB (1997) Proand anti-inflammatory cytokines in healthy volunteers fed various doses of fish oil for 1 year. European Journal of Clinical Investigation 27, 1003-1008.

Blok WL, Katan MB \& van der Meer JWM (1996) Modulation of inflammation and cytokine production by dietary (n-3) fatty acids. Journal of Nutrition 126, 1515-1533.

Broughton KS, Johnson CS, Pace BK, Liebman M \& Kleppinger KM (1997) Reduced asthma symptoms with n-3 fatty acid ingestion are related to 5-series leukotriene production. American Journal of Clinical Nutrition 65, 1011-1017.

Byleveld PM, Pang GT, Clancy RL \& Roberts DCK (1999) Fish oil feeding delays influenza virus clearance and impairs production of interferon- $\gamma$ and virus-specific immunoglobulin $\mathrm{A}$ in lungs of mice. Journal of Nutrition 129, 328-335.

Calder PC (1995) Fatty acids, dietary lipids and lymphocyte functions. Biochemical Society Transcations 23, 302-309.

Calder PC (1996a) Effects of fatty acids and dietary lipids on cells of the immune system. Proceedings of the Nutrition Society 55, $127-150$.

Calder PC (1996b) Immunomodulatory and anti-inflammatory effects of $n-3$ polyunsaturated fatty acids. Proceedings of the Nutrition Society 55, 737-774.

Calder PC (1997) N-3 polyunsaturated fatty acids and cytokine production in health and disease. Annals of Nutrition and Metabolism 41, 203-234.

Calder PC (1998a) Dietary fatty acids and the immune system. Nutrition Reviews 56, S70-S83.

Calder PC (1998b) N-3 fatty acids and mononuclear phagocyte function. In Medicinal Fatty Acids In Inflammation, pp. 1-27 [JM Kremer, editor]. Basle: Birkhauser Verlag.

Calder PC (1998c) Dietary fatty acids and lymphocyte functions. Proceedings of the Nutrition Society 57, 487-502.

Calder PC (2001) N-3 Fatty acids and rheumatoid arthritis. In Food and Nutritional Supplements in Health and Disease, pp. 175197 [JK Ransley, JK Donnelly and NW Read, editors]. London: Springer Verlag.

Calder PC \& Miles EA (2000) Fatty acids and atopic disease. Pediatric Allergy and Immunology 11, Suppl., 29-36.

Cannon JG, Fiatarone MA, Meydani M, Gong J, Scott L, Blumberg JB \& Evans WJ (1995) Aging and dietary modulation of elastase and interleukin-1 beta secretion. American Journal of Physiology 268, R208-R213.

Caughey GE, Mantzioris E, Gibson RA, Cleland LG \& James MJ (1996) The effect on human tumor necrosis factor $\alpha$ and interleukin $1 \beta$ production of diets enriched in n-3 fatty acids 
from vegetable oil or fish oil. American Journal of Clinical Nutrition 63, 116-122.

Cook ME, Miller CC, Park Y \& Pariza M (1993) Immune modulation by altered nutrient metabolism control of immuneinduced growth depression. Poultry Science 72, 1301-1305.

Cooper AL, Gibbons L, Horan MA, Little RA \& Rothwell NJ (1993) Effect of dietary fish oil supplementation on fever and cytokine production in human volunteers. Clinical Nutrition $\mathbf{1 2}$, 321-328.

Crevel RWR, Friend JV, Goodwin BFJ \& Parish WE (1992) High fat diets and the immune response of $\mathrm{C} 57 \mathrm{Bl}$ mice. British Journal of Nutrition 67, 17-26.

DeLuca P, Rossetti RG, Alavian C, Karim P \& Zurier RB (1999) Effects of gamma-linolenic acid on interleukin-1beta and tumor necrosis factor-alpha secretion by stimulated human peripheral blood monocytes: studies in vitro and in vivo. Journal of Investigative Medicine 47, 246-250.

DeMarco DM, Santoli D \& Zurier RB (1994) Effects of fatty acids on proliferation and activation of human synovial compartment lymphocytes. Journal of Leukocyte Biology 56, 612-615.

Endres S, Ghorbani R, Kelley VE, Georgilis K, Lonnemann G, van der Meer JMW, Cannon JG, Rogers TS, Klempner MS, Weber PC, Schaeffer EJ, Wolff SM \& Dinarello CA (1989) The effect of dietary supplementation with n-3 polyunsaturated fatty acids on the synthesis of interleukin-1 and tumor necrosis factor by mononuclear cells. New England Journal of Medicine 320, 265-271.

Endres S, Meydani SN, Ghorbani R, Schindler R \& Dinarello CA (1993) Dietary supplementation with n-3 fatty acids suppresses interleukin-2 production and mononuclear cell proliferation. Journal of Leukocyte Biology 54, 599-603.

Feng C, Keisler DH \& Fritsche KL (1999) Dietary omega-3 polyunsaturated fatty acids reduce IFN-gamma receptor expression in mice. Journal of Interferon and Cytokine Research 19, 41-48.

Friend JV, Lock SO, Gurr MI \& Parish WE (1980) Effect of different dietary lipids on the immune responses of Hartley strain guinea pigs. International Archives of Allergy and Applied Immunology 62, 292-301.

Gallai V, Sarchielli P, Trequattrini A, Franceschini M, Floridi A, Firenze C, Alberti A, Di Benedetto D \& Stragliotto E (1993) Cytokine secretion and eicosanoid production in the peripheral blood mononuclear cells of MS patients undergoing dietary supplementation with n-3 polyunsaturated fatty acids. Journal of Neuroimmunology 56, 143-153.

Geusens PP (1998) n-3 Fatty acids in the treatment of rheumatoid arthritis. In Medicinal Fatty Acids in Inflammation, pp. 111-123 [J Kremer, editor]. Basel: Birkhauser Verlag.

Gibney MJ \& Hunter B (1993) The effects of short- and long-term supplementation with fish oil on the incorporation of n-3 polyunsaturated fatty acids into cells of the immune system in healthy volunteers. European Journal of Clinical Nutrition 47, 255-259.

Gold KN, Weyand CM \& Goronzy JJ (1994) Modulation of helper T cell function by prostaglandins. Arthritis and Rheumatism 37, 925-933.

Goldyne ME (1988) Lymphocytes and arachidonic acid metabolism. Progress in Allergy 44, 140-152.

Grimble RF (1998) Dietary lipids and the inflammatory response. Proceedings of the Nutrition Society 57, 535-542.

Harbige LS (1998) Dietaty n-6 and n-3 fatty acids in immunity and autoimmune disease. Proceedings of the Nutrition Society 57, $555-562$.

Hayek MG, Han SN, Wu D, Watkins BA, Meydani M, Dorsey JL, Smith DE \& Meydani SN (1999) Dietary conjugated linoleic acid influences the immune response of young and old C57BL/6NCrlBR mice. Journal of Nutrition 129, 32-38.
Haynes DR, Whitehouse MW \& Vernon-Roberts B (1992) The prostaglandin $\mathrm{E}_{1}$ analogue, Misoprostol, regulates inflammatory cytokines and immune functions in vitro like the natural prostaglandins $\mathrm{E}_{1}, \mathrm{E}_{2}$ and $\mathrm{E}_{3}$. Immunology 76, 251-257.

Healy D, Wallace FA, Miles EA, Calder PC \& Newsholme P (2000) The effect of low to moderate amounts of dietary fish oil on neutrophil lipid composition and function. Lipids 35, $763-768$.

Hebert JR, Barone J, Reddy MM \& Backlund JY (1990) Natural killer cell activity in a longitudinal dietary fat intervention trial. Clinical Immunology and Immunopathology 54, 103-116.

Hodge L, Peat JK \& Salome C (1994) Increased consumption of polyunsaturated oils may be a cause of increased prevalence of childhood asthma. Australian and New Zealand Journal of Medicine 24, 727.

Hughes DA (1998) In vitro and in vivo effects of $\mathrm{n}-3$ polyunsaturated fatty acids on human monocyte function. Proceedings of the Nutrition Society 57, 521-525.

Hughes DA \& Pinder AC (1997) N-3 Polyunsaturated fatty acids modulate the expression of functionally associated molecules on human monocytes and inhibit antigen presentation in vitro. Clinical and Experimental Immunology 110, 516-523.

Hughes DA, Pinder AC, Piper Z, Johnson IT \& Lund EK (1996b) Fish oil supplementation inhibits the expression of major histocompatibility complex class II molecules and adhesion molecules on human monocytes. American Journal of Clinical Nutrition 63, 267-272.

Hughes DA, Southon S \& Pinder AC (1996a) (n-3) Polyunsaturated fatty acids modulate the expression of functionally associated molecules on human monocytes in vitro. Journal of Nutrition 126, 603-610.

Iverson L, Fogh K \& Bojesen G (1991) Linoleic acid and dihomogammalinolenic acid inhibit leukotriene formation and stimulate the formation of their 15 lipoxygenase products by human neutrophils in vitro. Evidence for the formation of antiinflammatory compounds. Agents and Actions 33, 286-291.

Iverson L, Fogh K \& Kragbelle K (1992) Effect of dihomogammalinolenic acid and its 15 lipoxygenase metabolite on eicosanoid metabolism by human mononuclear leukocytes in vitro: Selective inhibition of the 5 lipoxygenase pathway. Archives of Dermatological Research 284, 222-226.

James MJ \& Cleland LG (1997) Dietary n-3 fatty acids and therapy for rheumatoid arthritis. Seminars in Arthritis and Rheumatism 27, 85-97.

Jeffery NM, Newsholme EA \& Calder PC (1997) The level of polyunsaturated fatty acids and the $n-6$ to $n-3$ polyunsaturated fatty acid ratio in the rat diet both affect serum lipid levels and lymphocyte functions. Prostaglandins Leukotrienes and Essential Fatty Acids 57, 149-160.

Johnson MM, Swan DD, Surette ME, Stegner J, Chilton T, Fonteh AN \& Chilton FH (1997) Dietary supplementation with $\gamma$ linolenic acid alters fatty acid content and eicosanoid production in healthy humans. Journal of Nutrition 127, 1435-1444.

Jolly CA, Jiang Y-H, Chapkin RS \& McMurray DN (1997) Dietary (n-3) polyunsaturated fatty acids suppress murine lymphoproliferation, interleukin-2 secretion and the formation of diacylglycerol and ceramide. Journal of Nutrition 127, 37-43.

Kelley DS, Branch LB \& Iacono JM (1989) Nutritional modulation of human immune status. Nutrition Research 9, 965-975.

Kelley DS, Branch LB, Love JE, Taylor PC, Rivera YM \& Iacono JM (1991) Dietary alpha-linolenic acid and immunocompetence in humans. American Journal of Clinical Nutrition 53, 40-46.

Kelley DS, Dougherty RM, Branch LB, Taylor PC \& Iacono JM (1992) Concentration of dietary n-6 polyunsaturated fatty acids and human immune status. Clinical Immunology and Immunopathology 62, 240-244.

Kelley DS, Taylor PC, Nelson GJ \& Mackey BE (1998b) Dietary 
docosahexaenoic acid and immunocompetence in young healthy men. Lipids 33, 559-566.

Kelley DS, Taylor PC, Nelson GJ, Schmidt PC, Ferretti A, Erickson KL, Yu R, Chandra RK \& Mackey BE (1999) Docosahexaenoic acid ingestion inhibits natural killer cell activity and production of inflammatory mediators in young healthy men. Lipids 34, 317-324.

Kelley DS, Taylor PC, Nelson GJ, Schmidt PC, Mackey BE \& Kyle D (1997) Effects of dietary arachidonic acid on human immune response. Lipids 32, 449-456.

Kelley DS, Taylor PC, Nelson GJ \& Mackey BE (1998a) Arachidonic acid supplementation enhances synthesis of eicosanoids without suppressing immune functions in young healthy men. Lipids 33, 125-130.

Kelly JP \& Parker CW (1979) Effect of arachidonic acid and other unsaturated fatty acids on mitogenesis in human lymphocytes. Journal of Immunology 122, 1556-1562.

Khair-El-Din TA, Sicher SC, Vazquez MA, Wright WJ \& Lu CY (1995) Docosahexaenoic acid, a major constituent of fetal serum and fish oil diets, inhibits IFN $\gamma$-induced Ia-expression by murine macrophages in vitro. Journal of Immunology 154, 1296-1306.

Kinsella JE, Lokesh B, Broughton S \& Whelan J (1990) Dietary polyunsaturated fatty acids and eicosanoids: potential effects on the modulation of inflammatory and immune cells: An overview. Nutrition 6, 24-44.

Lee TH, Hoover RL, Williams JD, Sperling RI, Ravalese J, Spur BW, Robinson DR, Corey EJ, Lewis RA \& Austen KF (1985) Effects of dietary enrichment with eicosapentaenoic acid and docosahexaenoic acid on in vitro neutrophil and monocyte leukotriene generation and neutrophil function. New England Journal of Medicine 312, 1217-1224.

Leslie CA, Gonnerman WA, Ullman MD, Hayes KC, Franzblau C \& Cathcart ES (1985) Dietary fish oil modulates macrophage fatty acids and decreases arthritis susceptibility in mice. Journal of Experimental Medicine 162, 1336-1349.

Lewis RA, Austen KF \& Soberman RJ (1990) Leukotrienes and other products of the 5-lipoxygenase pathway: Biochemistry and relation to pathobiology in human diseases. New England Journal of Medicine 323, 645-655.

Linos A, Kaklamanis E, Kontomerkos A, Koumantaki Y, Gazi S, Vaiopoulos G, Tsokos GC \& Kaklamanis PH (1991) The effect of olive oil and fish consumption on rheumatoid arthritis - a case control study. Scandanavian Journal of Rheumatology $\mathbf{2 0 ,}$ 419-426.

Matsuo N, Osada K, Kodama T, Lim BO, Nakao A, Yamada K \& Sugano M (1996) Effects of $\gamma$-linolenic acid and its positional isomer pinolenic acid on immune parameters of Brown Norway rats. Prostaglandins Leukotrienes and Essential Fatty Acids $\mathbf{5 5}$, 223-229.

Meydani SN, Endres S, Woods MM, Goldin BR, Soo C, MorrillLabrode A, Dinarello C \& Gorbach SL (1991) Oral (n-3) fatty acid supplementation suppresses cytokine production and lymphocyte proliferation: comparison between young and older women. Journal of Nutrition 121, 547-555.

Meydani SN, Lichtenstein AH, Cornwall S, Meydani M, Goldin BR, Rasmussen H, Dinarello CA \& Schaefer EJ (1993) Immunologic effects of national cholesterol education panel step-2 diets with and without fish-derived n-3 fatty acid enrichement. Journal of Clinical Investigation 92, 105-113.

Miles EA \& Calder PC (1998) Modulation of immune function by dietary fatty acids. Proceedings of the Nutrition Society 57, 277-292.

Molvig J, Pociot F, Worsaae H, Wogensen LD, Baek L, Christensen P, Mandrup-Poulsen T, Andersen K, Madsen P, Dyerberg J \& Nerup J (1991) Dietary supplementation with $\omega-3$ polyunsaturated fatty acids decreases mononuclear cell proliferation and interleukin- $1 \beta$ content but not monokine secretion in healthy and insulin-dependent diabetic individuals. Scandanavian Journal of Immunology 34, 399-410.

Mossmann TR \& Sad S (1996) The expanding universe of T-cell subsets: Th1, Th2 and more. Immunology Today 17, 138-146.

Peterson LD, Jeffery NM, Thies F, Sanderson P, Newsholme EA \& Calder PC (1998a) Eicosapentaenoic and docosahexaenoic acids alter rat spleen leukocyte fatty acid composition and prostaglandin $E_{2}$ production but have different effects on lymphocyte functions and cell-mediated immunity. Lipids 33, $171-180$.

Peterson LD, Thies F, Sanderson P, Newsholme EA \& Calder PC (1998b) Low levels of eicosapentaenoic and docosahexaenoic acids mimic the effects of fish oil upon rat lymphocytes. Life Sciences 62, 2209-2217.

Peterson LD, Thies F \& Calder PC (1999) Dose-dependent effects of dietary $\gamma$-linolenic acid on rat spleen lymphocyte functions. Prostaglandins Leukotrienes and Essential Fatty Acids 61, 19-24.

Prickett JD, Robinson DR \& Bloch KJ (1982) Enhanced production of $\operatorname{IgE}$ and $\mathrm{IgG}$ antibodies associated with a diet enriched in eicosapentaenoic acid. Immunology 46, 819-826.

Pullman-Moar S, Laposata M, Lern D, Holman RT, Leventhal LJ, De Marco D \& Zurier RB (1990) Alteration of the cellular fatty acid profile and the production of eicosanoids in human monocytes by gamma-linolenic acid. Arthritis and Rheumatism 33, $1526-1533$.

Purasiri P, McKechnie A, Heys SD \& Eremin O (1997) Modulation in vitro of human natural cytotoxicity, lymphocyte proliferative response to mitogens and cytokine production by essential fatty acids. Immunology 92, 166-172.

Rasmussen LB, Kiens B, Pedersen BK \& Richter EA (1994) Effect of diet and plasma fatty acid composition on immune status in elderly males. American Journal of Clinical Nutrition 59, 572-577.

Rodgers JB (1998) n-3 Fatty acids in the treatment of ulcerative colitis. In Medicinal Fatty Acids in Inflammation, pp. 103-109 [J Kremer, editor]. Basel: Birkhauser Verlag.

Roper RL \& Phipps RP (1994) Prostaglandin $E_{2}$ regulation of the immune response. Advances in Prostaglandin, Thromboxane and Leukotriene Research 22, 101-111.

Rossetti RG, Seiler CM, DeLuca P, Laposata M \& Zurier RB (1997) Oral administration of unsaturated fatty acids: effects on human peripheral blood T lymphocyte proliferation. Journal of Leukocyte Biology 62, 438-443.

Sanderson P \& Calder PC (1998) Dietary fish oil diminishes lymphocyte adhesion to macrophage and endothelial cell monolayers. Immunology 94, 79-87.

Sanderson P, Yaqoob P \& Calder PC (1995a) Effects of dietary lipid manipulation upon rat spleen lymphocyte functions and the expression of lymphocyte surface molecules. Journal of Nutritional and Environmental Medicine 5, 119-132.

Sanderson P, Yaqoob P \& Calder PC (1995b) Effects of dietary lipid manipulation upon graft vs. host and host vs. graft responses in the rat. Cellular Immunology 164, 240-247.

Santoli D, Phillips PD, Colt TL \& Zurier RB (1990) Suppression of interleukin-2-dependent human $\mathrm{T}$ cell growth in vitro by prostaglandin E (PGE) and their precursor fatty acids. Journal of Clinical Investigation 85, 424-432.

Schmidt EB, Varming K, Moller JM, Bulow Pederson I, Madsen P \& Dyerberg J (1996) No effect of a very low dose of n-3 fatty acids on monocyte function in healthy humans. Scandanavian Journal of Clinical Investigation 56, 87-92.

Sperling RI (1998) The effects of n-3 polyunsaturated fatty acids on neutrophils. Proceedings of the Nutrition Society 57, 527-534.

Sperling RI, Benincaso AI, Knoell CT, Larkin JK, Austen KF \& Robinson DR (1993) Dietary $\omega-3$ polyunsaturated fatty acids 
inhibit phosphoinositide formation and chemotaxis in neutrophils. Journal of Clinical Investigation 91, 651-660.

Thies F, Nebe-von-Caron G, Powell JR, Yaqoob P, Newsholme EA \& Calder PC (2001a) Dietary supplementation with eicosapentaenoic acid, but not with other long chain n-3 or n-6 polyunsaturated fatty acids, decreases natural killer cell activity in healthy subjects aged $>55 \mathrm{y}$. American Journal of Clinical Nutrition 73, 539-548.

Thies F, Nebe-von-Caron G, Powell JR, Yaqoob P, Newsholme EA \& Calder PC (2001b) Dietary supplementation with $\gamma$ linolenic acid or with fish oil decreases $\mathrm{T}$ lymphocyte proliferation in healthy older humans. Journal of Nutrition 131, 1918-1927.

Thies F, Miles EA, Nebe-von-Caron G, Powell JR, Hurst TL, Newsholme EA \& Calder PC (2001c) Influence of dietary supplementation with long chain n-3 or n-6 polyunsaturated fatty acids on blood inflammatory cell populations and functions and on plasma soluble adhesion molecules in healthy adults. Lipids in press.

Turek JJ, Li Y, Schoenlein IA, Allen KGD \& Watkins BA (1998) Modulation of macrophage cytokine production by conjugated linoleic acids is influenced by the dietary n-6:n-3 fatty acid ratio. Journal of Nutritional Biochemistry 9, 258-266.

Vilaseca J, Salas A, Guarner F, Rodriguez R, Martinez M \& Malagelada J-R (1990) Dietary fish oil reduces progresssion of chronic inflammatory lesions in a rat model of granulomatous colitis. Gut 31, 539-544.

Volker DH, FitzGerald PEB \& Garg ML (2000) The eicosapentaenoic to docosahexaenoic acid ratio of diets affects the pathogenesis of arthritis in Lew/SSN rats. Journal of Nutrition 130, 559-565.

Wallace FA, Miles EA, Evans C, Stock TE, Yaqoob P \& Calder PC (2001) Dietary fatty acids influence the production of Th1- but not Th2-type cytokines. Journal of Leukocyte Biology 69, 449-457.

Wallace JL, Keenan CM \& Finn NJ (1989) Anti-inflammatory effects of a fish oil diet in a rat model of chronic colitis. Gastroenterology 96, A535.

Watson J, Byars ML, McGill P \& Kelman AW (1993) Cytokine and prostaglandin production by monocytes of volunteers and rheumatoid arthritis patients treated with dietary supplements of blackcurrant seed oil. British Journal of Rheumatology 32, 1055-1058.
Wu D \& Meydani SN (1998) n-3 Polyunsaturated fatty acids and immune function. Proceedings of the Nutrition Society 57, 503-509.

Wu D, Meydani M, Leka LS, Nightingale Z, Handelman GJ, Blumberg JB \& Meydani SN (1999) Effect of dietary supplementation with black currant seed oil on the immune response of healthy elderly subjects. American Journal of Clinical Nutrition 70, 536-543.

Yaqoob P (1998a) Monounsaturated fats and immune function. Proceedings of the Nutrition Society 57, 511-520.

Yaqoob P (1998b) Lipids and the immune response. Current Opinion in Clinical Nutrition and Metabolic Care 1, 153-161.

Yaqoob P, Knapper J, Webb D, Williams C, Newsholme EA \& Calder PC (1998) Effect of olive oil on immune function in middle-aged men. American Journal of Clinical Nutrition 67, $129-135$.

Yaqoob P, Newsholme EA \& Calder PC (1994a) The effect of dietary lipid manipulation on rat lymphocyte subsets and proliferation. Immunology 82, 603-610.

Yaqoob P, Newsholme EA \& Calder PC (1994b) Inhibition of natural killer cell activity by dietary lipids. Immunology Letters 41, 241-247.

Yaqoob P, Newsholme EA \& Calder PC (1995) The effect of dietary lipid manipulation on leucocyte proliferation in whole blood. Nutrition Research 15, 279-287.

Yaqoob P, Newsholme EA \& Calder PC (1999) Comparison of cytokine production in cultures of whole human blood and purified mononuclear cells. Cytokine 11, 600-605.

Yaqoob P, Pala HS, Cortina-Borja M, Newsholme EA \& Calder PC (2000) Encapsulated fish oil enriched in $\alpha$-tocopherol alters plasma phospholipid and mononuclear cell fatty acid compositions but not mononuclear cell functions. European Journal of Clinical Investigation 30, 260-274.

Ziboh VA (1998) The role of n-3 fatty acids in psoriasis. In Medicinal Fatty Acids in Inflammation, pp. 45-53 [J Kremer, editor]. Basel: Birkhauser Verlag.

Zurier RB, Rossetti RG, Seiler CM \& Laposata M (1999) Human peripheral blood $\mathrm{T}$ lymphocyte proliferation after activation of the $\mathrm{T}$ cell receptor: effects of unsaturated fatty acids. Prostaglandins Leukotrienes and Essential Fatty Acids 60, $371-375$. 